\title{
MXene Sorbents for Removal of Urea from Dialysate - a Step Towards the Wearable Artificial Kidney
}

Fayan Meng, ${ }^{1,2}$ Mykola Seredych, ${ }^{1}$ Chi Chen, ${ }^{1,3}$ Victor Gura, ${ }^{4}$ Sergey Mikhalovsky, ${ }_{5}^{5,6}$ Susan Sandeman, ${ }^{5}$ Ganesh Ingavle, ${ }^{5,7}$ Tochukwu Ozulumba, ${ }^{5}$ Ling Miao, ${ }^{3}$ Babak Anasori ${ }^{* 1}$, and Yury Gogotsi ${ }^{1}$

1

A.J. Drexel Nanomaterials Institute, and Materials Science and Engineering Department, Drexel University, 3141 Chestnut Street, Philadelphia, PA 19104, USA.

2

Pharmaceutical College, Guangxi Medical University, Nanning, Guangxi, 530021, People's Republic of China.

3

School of Optical and Electronic Information, Huazhong University of Science and Technology, Wuhan, Hubei 430074, People's Republic of China.

4

Cedars Sinai Medical Center. UCLA The David Geffen School of Medicine, 50 N. la Cienega Blvd. Suite 310, Beverly Hills, CA 90211, USA.

5

Biomaterials and Medical Devices Research Group, School of Pharmacy and Biomolecular

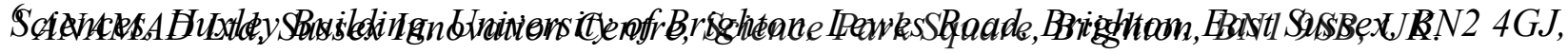
$U K$.

${ }^{7}$ Symbiosis Centre for Stem Cell Research, Symbiosis International University, Lavale, Pune412115, India

* Corresponding authors:

Anasori@drexel.edu

Gogotsi@drexel.edu 
ABSTRACT: The wearable artificial kidney can deliver continuous ambulatory dialysis for more than 3 million patients with end-stage renal disease. However, the efficient removal of urea is a key challenge in miniaturizing the device and making it light and small enough for practical use. Here, we show that two-dimensional titanium carbide (MXene) with the composition of $\mathrm{Ti}_{3} \mathrm{C}_{2} \mathrm{~T}_{x}$, where $\mathrm{T}_{x}$ represents surface termination groups such as $-\mathrm{OH},-\mathrm{O}-$, and $-\mathrm{F}$, can adsorb urea, reaching $99 \%$ removal efficiency from aqueous solution and $94 \%$ from dialysate at the initial urea concentration of $30 \mathrm{mg} / \mathrm{dL}$, with the maximum urea adsorption capacity of $10.4 \mathrm{mg} / \mathrm{g}$ at room temperature. When tested at $37{ }^{\circ} \mathrm{C}$, we achieved a twofold increase in the urea removal efficiency from dialysate, with the maximum urea adsorption capacity of $21.7 \mathrm{mg} / \mathrm{g}$. $\mathrm{Ti}_{3} \mathrm{C}_{2} \mathrm{~T}_{x}$ showed good hemocompatibility; it did not induce cell apoptosis or reduce metabolising cell fraction indicating no impact on cell viability at concentrations of up to $200 \mu \mathrm{g} / \mathrm{mL}$. The biocompatibility of $\mathrm{Ti}_{3} \mathrm{C}_{2} \mathrm{~T}_{x}$ and its selectivity for urea adsorption from dialysate open a new opportunity in designing a miniaturized dialysate regeneration system for a wearable artificial kidney.

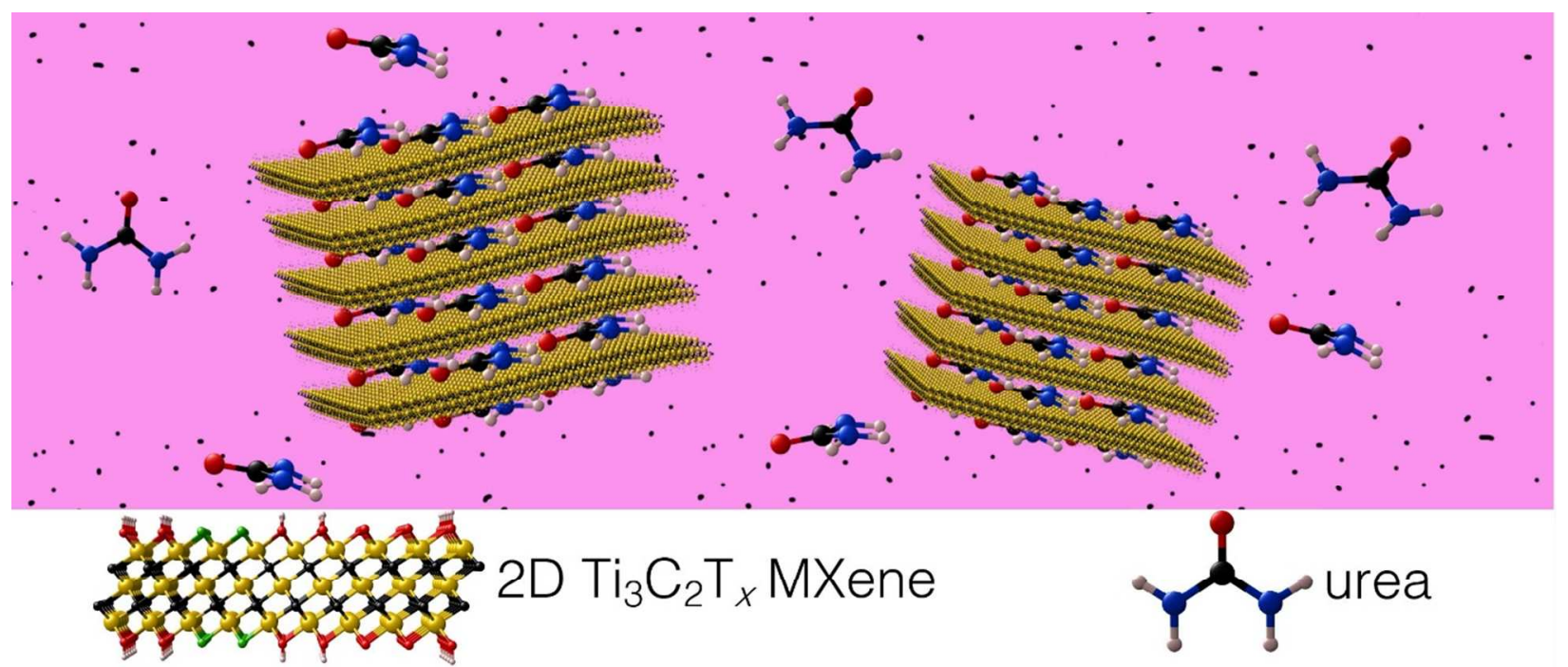

KEYWORDS: urea, adsorption, dialysate, wearable artificial kidney, MXenes, 2D materials 
End Stage Renal Disease (ESRD) currently affects more than 3 million people worldwide. ${ }^{1}$ Dialysis or a kidney transplant are the only alternatives for these patients to avoid death but only few are fortunate to have a kidney transplant and the vast majority depend on dialysis for the rest of their life. The quality of life of patients on chronic dialysis is poor and the mortality is high. Most patients are disabled, and many cannot carry out normal activities of daily life.

It is increasingly evident that more frequent and longer dialysis treatment is required for improved outcomes in these patients. The current practice of blood filtration for 9 to 12 hours per week with dialysis, as typically prescribed, is both un-physiologic and mostly inadequate. In contrast, more frequent and longer dialysis is associated with far better outcomes. ${ }^{2}$ Furthermore, in healthy humans, blood is continuously filtered by kidneys, that is 168 hours a week, maintaining perfect homeostasis of electrolytes, acid-base equilibrium and fluid balance. As such, imitating the nonstop filtration may be a worthy goal to achieve better health and quality of life in ESRD patients leading to the concept of a wearable artificial kidney (WAK), which is continuously used by the patient and does not require regular attendance to a dialysis centre several times a week.

A portable device that can be worn continuously, first suggested a few decades ago as an alternative to conventional dialysis, would allow patients greater mobility and offer better quality of life. ${ }^{3,4}$ Although previous attempts to build a WAK did not result in a device that could present an alternative to ongoing dialysis, this has been recently accomplished in bench, animal, and human trials. ${ }^{5-9}$

A major challenge in further reduction of the weight and size of a WAK for wearability, is the need to substantially reduce the volume and weight of the system for dialysate regeneration, currently performed using adsorbents. ${ }^{4}$ However, dialysate regeneration by sorption has always 
faced the intractable problem of urea removal. Although urea per se is not toxic, its removal is necessary to maintain adequate nitrogen balance. To date, no material has been found which could efficaciously retain urea by physical sorption. ${ }^{10}$ So far, urea is removed from dialysate by decomposing it into ammonia and $\mathrm{CO}_{2}$ using the immobilized enzyme urease according to the reaction:

$$
\left(\mathrm{NH}_{2}\right)_{2} \mathrm{CO}+\mathrm{H}_{2} \mathrm{O} \rightarrow 2 \mathrm{NH}_{3}+\mathrm{CO}_{2}
$$

Carbon dioxide is usually vented into the atmosphere and the ammonia is adsorbed by zirconium hydrophosphate. ${ }^{11}$ This was the method realized in the REDY (REcirculation of DialYsate) machine, the first commercialized home sorbent dialysis system that was used for many years but is no longer produced or supported. The current version of WAK effectively removes urea using the same method. However, the production of $\mathrm{CO}_{2}$ in a wearable device poses significant technical obstacles, ${ }^{8,12}$ and the amount of sorbent required for this process makes the device too voluminous and heavy to make it acceptable for the patients to wear. Therefore, there is an unmet need to provide an alternative method to separate urea from dialysate. The challenge of developing an efficient sorbent for urea removal remains unresolved. We have summarized the previous studies on different materials tested for urea adsorption in the Supporting Information.

The rationale behind this work is based on the unique properties of a new class of nanomaterials called MXenes, discovered in 2011. ${ }^{13}$ MXenes are a family of two-dimensional (2D) transition metal carbides and nitrides with a general formula of $\mathrm{M}_{n+1} \mathrm{X}_{n} \mathrm{~T}_{x}$, where $\mathrm{M}$ stands for an early transition metal (e.g., Ti, $\mathrm{V}, \mathrm{Nb}, \mathrm{Mo}$ ), $\mathrm{X}$ is carbon and/or nitrogen, $n=1-3$, and $\mathrm{T}_{x}$ represents surface terminations such as $-\mathrm{OH},-\mathrm{O}-$ and $-\mathrm{F} .{ }^{13,14}$ More than 20 different MXenes 
have been synthesized and many more are predicted to exist. ${ }^{14}$ Their physical and chemical properties can be finely tuned by varying their structures and conditions of their synthesis. ${ }^{14}$

MXene 2D nanosheets are $\sim 1-n m-$ thick made of 2-4 atomic layers of a transition metal interleaved with carbon or nitrogen with surface terminations bonded to the outer metallic layers. MXenes are synthesized via a top-down method of selective extraction of atomic layers from layered ternary carbides in fluoride containing aqueous solutions. For example, $\mathrm{Ti}_{3} \mathrm{C}_{2} \mathrm{~T}_{x}$ powder is synthesized by selective extraction of aluminum layers from $\mathrm{Ti}_{3} \mathrm{AlC}_{2} \cdot{ }^{13,15}$ The resulting $\mathrm{Ti}_{3} \mathrm{C}_{2} \mathrm{~T}_{x}$ particles of a few microns in lateral size (Fig. 1a-b) comprise several 1-nm-thick 2D MXene sheets. In every $\mathrm{Ti}_{3} \mathrm{C}_{2} \mathrm{~T}_{x}$ MXene sheet (Fig. 1c) three layers of Ti atoms are separated with carbon atoms and the outer Ti layers are functionalized by $-\mathrm{OH},-\mathrm{O}-$, or $-\mathrm{F}\left(\mathrm{T}_{x}\right)$. Previous studies have shown that the surface functionality of MXenes varies depending on the MXene composition and synthesis route. ${ }^{16-19}$ The unique combination of a core transition metal carbide with surface functionalities makes MXenes conductive clay-resembling materials. ${ }^{20}$ Similar to clays, MXenes' layered structure can be intercalated and de-intercalated with water and organic molecules, such as hydrazine, urea, and cationic dyes. ${ }^{21-24}$ This suggests that the MXene structure could potentially be fine-tuned to adsorb urea by optimizing the interatomic and interlaminar distance of the material. Additionally, because MXenes surfaces are terminated with $-\mathrm{OH},-\mathrm{O}-$, and $-\mathrm{F}$, their affinity with urea could be further enhanced by forming hydrogen bonds on the surface.

Here, we present the results of urea adsorption by $\mathrm{Ti}_{3} \mathrm{C}_{2} \mathrm{~T}_{x}$, the most studied MXene, from aqueous solution and from discarded spent dialysate. To examine the effect of the MXene structure on their adsorption behaviour, two other MXenes were studied: $\mathrm{Ti}_{2} \mathrm{CT}_{x}$, a MXene with two layers of titanium and a layer of carbon, instead of 3 layers of titanium, ${ }^{14}$ and $\mathrm{Mo}_{2} \mathrm{TiC}_{2} \mathrm{~T}_{x}$, a 
MXene in which its outer titanium layers (Fig. 1a) are replaced by molybdenum. ${ }^{14,25}$ The density functional theory (DFT) has been applied to investigate the spatial orientation of urea molecules adsorbed on $\mathrm{Ti}_{3} \mathrm{C}_{2} \mathrm{~T}_{x}$ and estimate their corresponding adsorption energies. The biocompatibility of $\mathrm{Ti}_{3} \mathrm{C}_{2} \mathrm{~T}_{x}$ nanosheets was assessed by measuring their impact on the viability and metabolism of cells in direct contact with the MXene.

\section{RESULTS AND DISCUSSION}

Interaction between urea and MXenes. To understand the interaction between urea and MXenes, first-principle calculations of the adsorption behavior of urea on $\mathrm{Ti}_{3} \mathrm{C}_{2} \mathrm{~T}_{x}$ surface were performed. $\mathrm{Ti}_{3} \mathrm{C}_{2} \mathrm{~T}_{x}$ was considered with three possible surface terminations $(-\mathrm{OH},-\mathrm{O}-$ or $-\mathrm{F})$. The binding energy, $E_{\mathrm{b}}$, of urea on MXene surface is defined as:

$$
E_{\mathrm{b}}=E_{\mathrm{MXene}+\text { urea }}-\left(E_{\mathrm{MXene}}+E_{\text {urea }}\right),
$$

where $E_{\mathrm{MXene}+u r e a}$ is the total energy of MXene with a urea molecule, $E_{\mathrm{MXene}}$ is the total energy of MXene and $E_{\text {urea }}$ is the total energy of the urea molecule. The most stable adsorption configuration for each orientation (parallel or vertical, Fig. 1a) and their binding energies are shown in Fig. 1b. The binding energies range from -0.34 to $-0.93 \mathrm{eV}$ depending on MXenes surface terminations and orientation of the urea molecule. Our calculations show that regardless of surface terminations $(-\mathrm{OH},-\mathrm{O}-$, or $-\mathrm{F})$ the urea molecule prefers the parallel-to-surface configurations in the adsorbed state. This suggest ability of urea to intercalate between stacked MXene sheets. The most stable adsorption state of urea was on the $-\mathrm{OH}$ terminated surfaces with binding energy of -0.93 and $-0.8 \mathrm{eV}$ for the parallel and vertical orientations, respectively, followed by $-\mathrm{O}-$ and F-terminated surfaces (Fig. 1b). Higher stability of urea on the $-\mathrm{OH}$ terminated surfaces can be explained by the difference of charge density as shown in Fig. 1c, 
showing parallel urea adsorption configuration on MXene surfaces. There is a more significant charge transfer between urea and $-\mathrm{OH}$ terminated surface.

Our calculations show that urea adsorption affects the interlayer spacing of $\mathrm{Ti}_{3} \mathrm{C}_{2} \mathrm{~T}_{x}$. In general, the presence of urea in between the MXene layers expands the interlayer spacing (Fig. S1a). ${ }^{21}$ It is known that urea molecules can be protonated in acidic environment. ${ }^{26-28}$ Since MXene has acidic nature with $3 \times 10^{-2}$ moles of $\mathrm{H}^{+}$per mole of $\mathrm{MXene}^{20}$ and the surface $\mathrm{pH}$ 2.90, we have calculated the energy of interaction between protonated urea and $\mathrm{Ti}_{3} \mathrm{C}_{2} \mathrm{~T}_{x}$ surfaces as shown in Fig. S1b. The protonated urea may decompose on the $-\mathrm{OH}$ terminated surface, implying a strong interaction between them, and it shows strong adsorption on the $-\mathrm{O}-$ or Fterminated surfaces with binding energies of -4.10 and $-2.31 \mathrm{eV}$, respectively (Fig. S1b). Therefore, the attraction of urea and protonated urea to MXene surface suggests that adsorption of urea by MXene is thermodynamically favorable. ${ }^{26}$

Urea adsorption from aqueous solution. To validate our theoretical calculations, we first examined the adsorption of urea from aqueous solutions by $\mathrm{Ti}_{3} \mathrm{C}_{2} \mathrm{~T}_{x}$. The protocol for MXene synthesis is explained in the Methods section. In short, we used $10 \%$ hydrofluoric acid to selectively remove aluminum layers from $\mathrm{Ti}_{3} \mathrm{AlC}_{2} \cdot{ }^{13-15}$ After washing and removing the acidic solution, the resulting powder of $\mathrm{Ti}_{3} \mathrm{C}_{2} \mathrm{~T}_{x}$ (Fig. 1a), had particle size of a few microns (Fig. 1b). These particles consist of several 1-nm-thick 2D sheets of $\mathrm{Ti}_{3} \mathrm{C}_{2} \mathrm{~T}_{x}$ (Fig. 1c). The composition of surface functional groups $\left(\mathrm{T}_{x}\right)$ for this MXene (synthesized at similar conditions) was determined previously as $\mathrm{Ti}_{3} \mathrm{C}_{2}\left(\mathrm{O}_{0.13} \mathrm{OH}_{1.04} \mathrm{~F}_{0.83}\right)$ via atomic pair distribution function obtained by neutron scattering. ${ }^{16}$ It is worth noting that the $\mathrm{T}_{x}$ composition can change upon storage or by different treatments. ${ }^{19}$ 
a
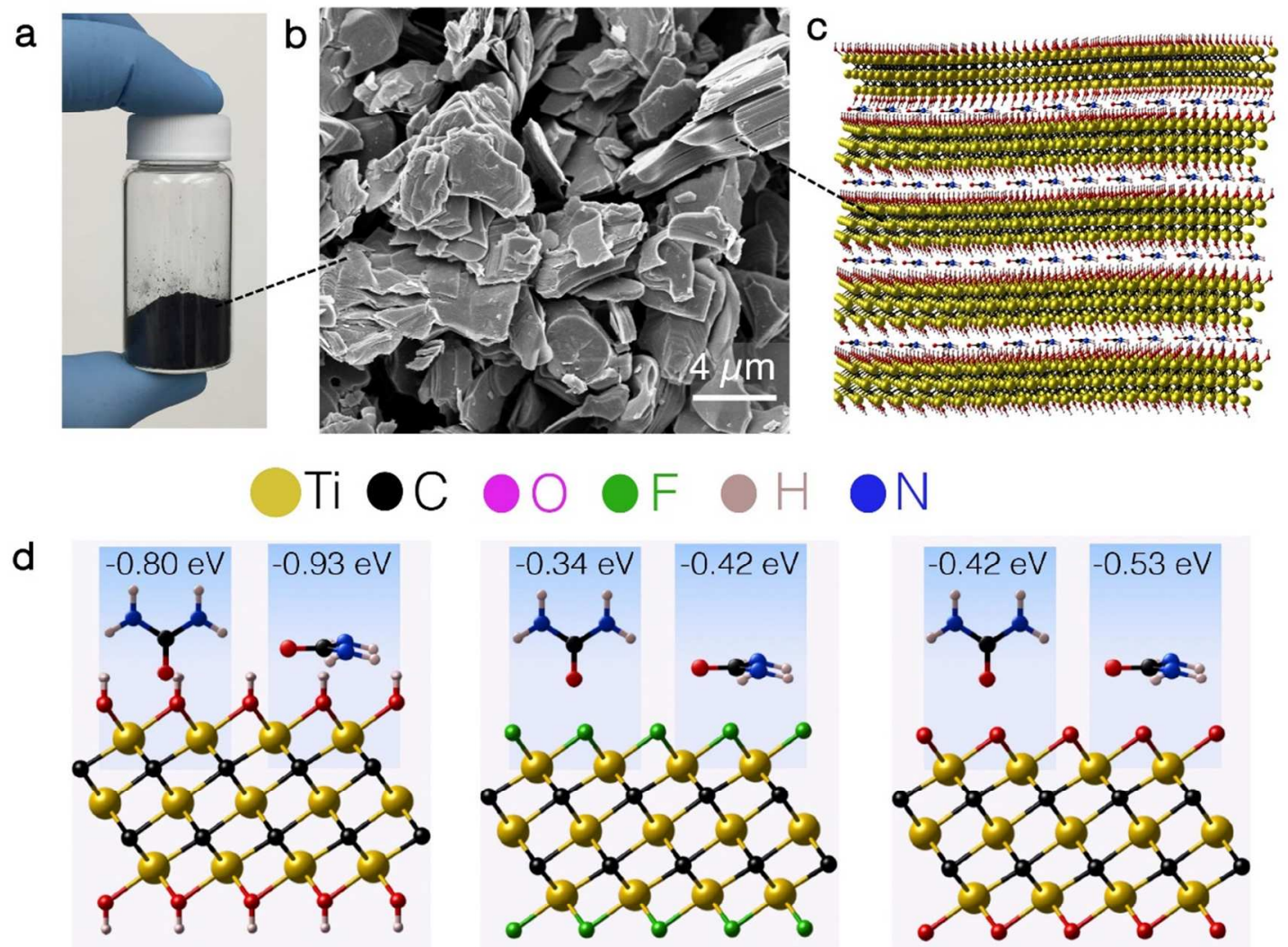

$-0.53 \mathrm{eV}$
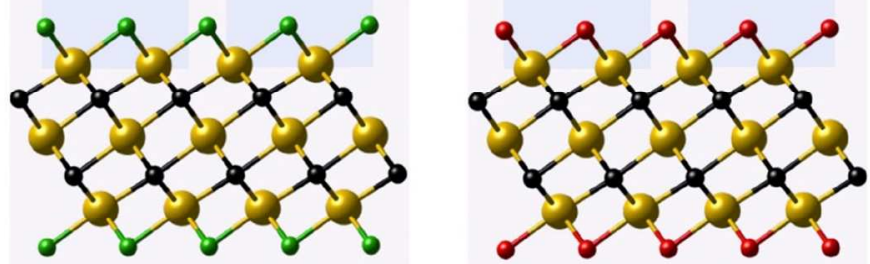

e

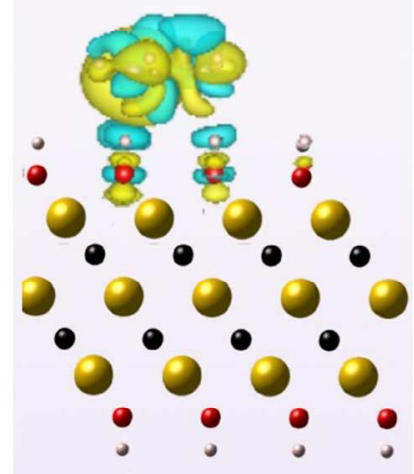

$\mathrm{OH}$-surface

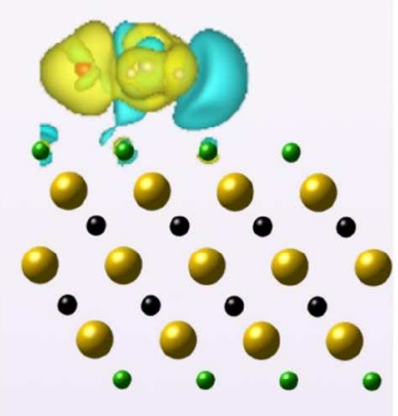

F-surface

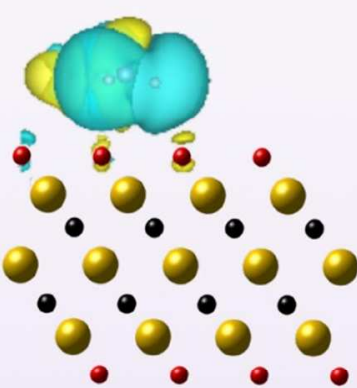

O-surface

Figure 1. Schematic representation of $\mathrm{Ti}_{3} \mathrm{C}_{2} \mathrm{~T}_{x}$ MXene, urea and their interaction computations. (a) digital photograph of $\sim 7$ grams of $\mathrm{Ti}_{3} \mathrm{C}_{2} \mathrm{~T}_{x}$ powder in a $20-\mathrm{mL}$ glass vial. (b) Scanning electron microscopy image of the $\mathrm{Ti}_{3} \mathrm{C}_{2} \mathrm{~T}_{x}$ powder. (c) Schematic of $\mathrm{Ti}_{3} \mathrm{C}_{2} \mathrm{~T}_{x}$ MXene powder intercalated with urea molecules. (d) Binding energies for normal and parallel configurations of urea on $\mathrm{Ti}_{3} \mathrm{C}_{2} \mathrm{~T}_{x}$ surfaces for three possible MXene terminations, $-\mathrm{OH},-\mathrm{F}$, and $-\mathrm{O}-$, showing urea most stable adsorption is parallel configuration to the $\mathrm{Ti}_{3} \mathrm{C}_{2} \mathrm{~T}_{x}$ MXene nanosheet. (e) Charge density for parallel configuration of urea on $\mathrm{Ti}_{3} \mathrm{C}_{2} \mathrm{~T}_{x}$ MXene surface with different surface terminations, showing more charge transfer between urea and $-\mathrm{OH}$ terminated surfaces (left panel). The turquoise and yellow regions indicate depletion and accumulation of electrons, respectively. 
To perform the quantitative analysis of urea removal from aqueous solution (Fig. 2a), we used the BioAssay Systems' urea assay kit method. ${ }^{29-31}$ Figure $2 \mathrm{~b}$ shows the results of urea adsorption from aqueous solution by $\mathrm{Ti}_{3} \mathrm{C}_{2} \mathrm{~T}_{x}$. The residual urea concentration decreased when $\mathrm{Ti}_{3} \mathrm{C}_{2} \mathrm{~T}_{x}$ MXene was added to the solution, and respectively the efficiency of urea adsorption significantly increased with increasing $\mathrm{Ti}_{3} \mathrm{C}_{2} \mathrm{~T}_{x}$ mass-loading from 0.155 to $5 \mathrm{~g}$. At the mass-loading of 5 and $2 \mathrm{~g}, \mathrm{Ti}_{3} \mathrm{C}_{2} \mathrm{~T}_{x}$ removed over $98 \%$ of urea within $4 \mathrm{~min}$. Even at the lowest mass-loading of $\mathrm{Ti}_{3} \mathrm{C}_{2} \mathrm{~T}_{x}, 0.155 \mathrm{~g}$, urea removal was as high as $80 \%$ (Fig. $2 \mathrm{c}$ ).

Since $\mathrm{Ti}_{3} \mathrm{C}_{2} \mathrm{~T}_{x}$ is just one of many MXene compositions, ${ }^{14}$ we investigated the urea adsorption kinetics by $\mathrm{Ti}_{2} \mathrm{CT}_{x}$ and $\mathrm{Mo}_{2} \mathrm{TiC}_{2} \mathrm{~T}_{x}$ at the same lowest mass-loading of $0.155 \mathrm{~g}$ (Fig. $2 \mathrm{~d}$ ). $\mathrm{Ti}_{2} \mathrm{CT}_{x}$ is a MXene with a similar composition as $\mathrm{Ti}_{3} \mathrm{C}_{2} \mathrm{~T}_{x}$, but it has thinner nanosheets due to presence of two titanium layers instead of three layers (Fig. 1c). $\mathrm{Mo}_{2} \mathrm{TiC}_{2} \mathrm{~T}_{x}$ was chosen to study the effect of different transition metals on MXene adsorption properties; in $\mathrm{Mo}_{2} \mathrm{TiC}_{2} \mathrm{~T}_{x}$ the outer titanium layers in the 2D structure (Fig. 1c) are replaced with molybdenum. We performed kinetic studies for 1 hour for all three MXenes. The results show fast urea adsorption by MXenes within 4 minutes (Fig. 2d), after which, small to no changes in its concentration were observed. The fast adsorption kinetics indicates that due to open interlayer structure urea molecules easily enter the interlamellar space forming hydrogen bonds with the hydrophilic surface functional groups such as $-\mathrm{OH}$ and $-\mathrm{O}-$ on MXenes. Among the three MXenes tested, $\mathrm{Ti}_{3} \mathrm{C}_{2} \mathrm{~T}_{x}$ showed the highest adsorption capacity of $9.7 \mathrm{mg} / \mathrm{g}$ for urea from aqueous solution at the lowest mass-loading of $0.155 \mathrm{~g}$ (Fig. 2d, and e). 
a



b

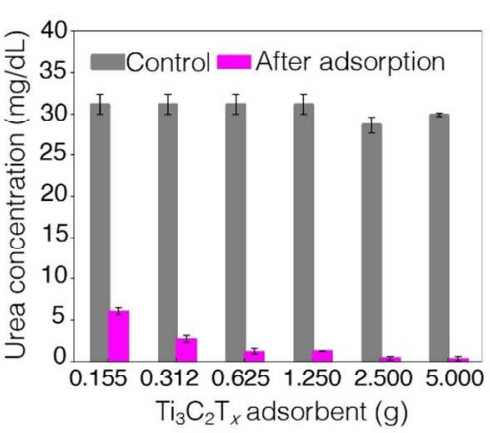

d

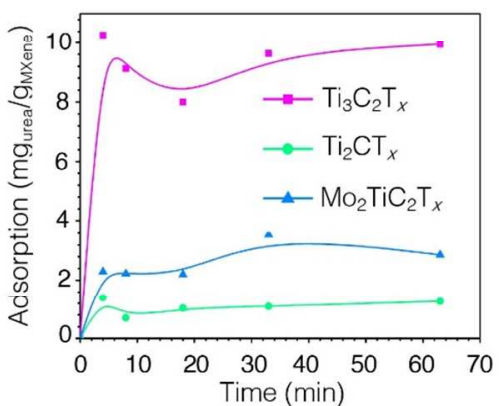

C

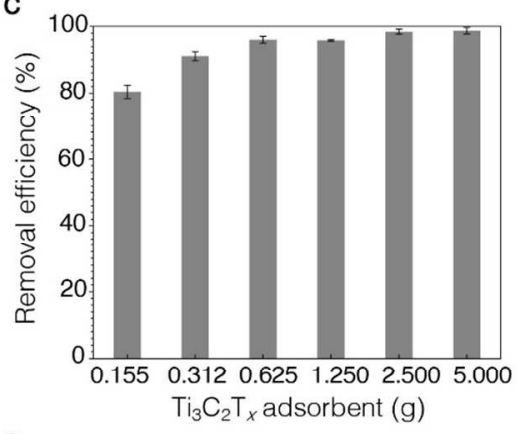

e

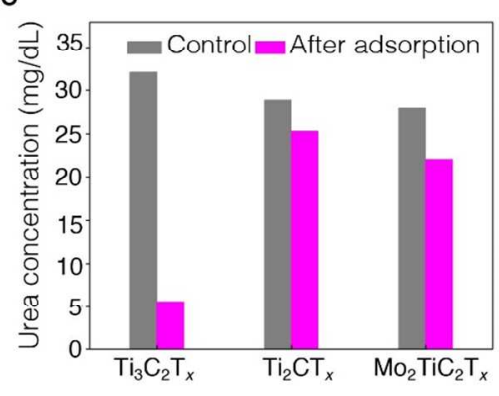

Figure 2. Adsorption of urea by MXenes from aqueous solution. (a) Schematic of MXene nanosheets used as the adsorbent. The beaker schematic is not to scale and should not be used to compare the size of MXene sheets and urea molecules. (b) Changes in urea concentration upon adsorption at different mass-loadings of $\mathrm{Ti}_{3} \mathrm{C}_{2} \mathrm{~T}_{x}$ (purple), compared to the control sample (gray). For each sample, the volume was $6 \mathrm{~mL}$ of $30 \mathrm{mg} / \mathrm{dL}$ of urea aqueous solution. The urea concentration was measured after adding MXene (contact time was $4 \mathrm{~min}$ ). (c) Urea removal efficiency in \% from aqueous solution at different mass-loadings of $\mathrm{Ti}_{3} \mathrm{C}_{2} \mathrm{~T}_{x}$. (d) Comparison of urea uptake for 1hour adsorption using different $2 \mathrm{D}$ MXenes, two types of titanium carbide $\left(\mathrm{Ti}_{3} \mathrm{C}_{2} \mathrm{~T}_{x}\right.$, squares and $\mathrm{Ti}_{2} \mathrm{CT}_{\mathrm{x}}$, triangles) and $2 \mathrm{D}$ molybdenum titanium carbide $\left(\mathrm{Mo}_{2} \mathrm{TiC}_{2} \mathrm{~T}_{x}\right.$, circles). MXene mass-loadings were $0.155 \mathrm{~g}$ in $6 \mathrm{~mL}$ of solution. (e) Comparison of urea concentration changes upon adsorption by $\mathrm{Ti}_{3} \mathrm{C}_{2} \mathrm{~T}_{x}, \mathrm{Ti}_{2} \mathrm{CT}_{x}$, and $\mathrm{Mo}_{2} \mathrm{TiC}_{2} \mathrm{~T}_{x}$ with initial urea concentration $\sim 30 \mathrm{mg} / \mathrm{dL}$. MXene mass-loading and adsorption time were $0.155 \mathrm{~g}$ and 4 minutes, respectively.

Figure 3 shows the equilibrium urea adsorption isotherms at room temperature and $37^{\circ} \mathrm{C}$ on $\mathrm{Ti}_{3} \mathrm{C}_{2} \mathrm{~T}_{x}$ and curve fitting of the experimental data using Langmuir, Freundlich and LangmuirFreundlich models. Based on our fittings, we estimated the adsorption capacity along with the corresponding adsorption constant $K$ for each model (Table S1). $K$ is a constant which characterizes the strength of adsorbate binding to the adsorbent, and $n$ is the heterogeneity factor indicating the degree of nonlinearity between solution concentration and adsorption. The Langmuir-Freundlich isotherm model presents a better fit than those of Langmuir and Freundlich isotherm models (Table S1). We calculated the maximum adsorption capacity $\left(q_{\mathrm{o}}\right)$ of $\mathrm{Ti}_{3} \mathrm{C}_{2} \mathrm{~T}_{x}$ 
adsorbent at room temperature from the Langmuir and Langmuir-Freundlich models to be 7.5 and $10.4 \mathrm{mg} / \mathrm{g}$, respectively, which are close to the measured adsorption capacity of $\mathrm{Ti}_{3} \mathrm{C}_{2} \mathrm{~T}_{x}(9.7$ $\mathrm{mg} / \mathrm{g}$, Fig. 2d) at room temperature. At $21.7 \mathrm{mg} / \mathrm{g}$, the adsorption from aqueous solution at $37^{\circ} \mathrm{C}$ showed a twofold increase in urea adsorption capacity compared with the value of $10.4 \mathrm{mg} / \mathrm{g}$ obtained at room temperature (Fig. 3 and Table S1). To further study the effect of temperature, we measured $\mathrm{Ti}_{3} \mathrm{C}_{2} \mathrm{~T}_{x}$ adsorption at $60{ }^{\circ} \mathrm{C}$ as well (Table $\mathrm{S} 1$ and Fig. S2). It is worth mentioning that the fitting parameters in the Langmuir-Freundlich equation, $K$ and $n$, have similar values at all three temperatures studied indicating the availability of the same surface for interaction with urea and the same mechanism of adsorption.

The Langmuir isotherm theory assumes monolayer coverage of adsorbate over a homogeneous adsorbent surface. ${ }^{32}$ Once the adsorption site is filled, no further sorption can take place at that site. This indicates that the surface reaches a saturation point where the maximum adsorption of the surface is achieved. ${ }^{33}$ The Freundlich isotherm theory is used to describe heterogeneous systems and assumes that as the adsorbate concentration increases, its concentration on the adsorbent surface increases as well. ${ }^{34}$ The $q_{\mathrm{o}}$ calculated from the LangmuirFreundlich fit is the closest to the measured adsorption capacity, suggesting the heterogeneous adsorption of urea on $\mathrm{Ti}_{3} \mathrm{C}_{2} \mathrm{~T}_{x}$. When we used a high urea concentration, up to $3 \mathrm{~g} / \mathrm{dL}$, the adsorption capacity of MXene reached $100 \mathrm{mg} / \mathrm{g}$ (Fig. S3). At high equilibrium concentrations of urea in the solution, the adsorption capacity significantly increases, indicating no saturation limit for $\mathrm{Ti}_{3} \mathrm{C}_{2} \mathrm{~T}_{x}$ MXene up to $3 \mathrm{~g} / \mathrm{dL}$ of urea equilibrium concentration. These experiments also suggest that a small fraction of urea molecules underwent hydrolysis into ammonium carbamate on the surface $\mathrm{Ti}_{3} \mathrm{C}_{2} \mathrm{~T}_{x}$ MXene identified in Fourier-transform infrared spectroscopy (FTIR) spectra (Fig. S4). However, the peak characteristic of ammonium carbamate was noticeable only 
at very high concentration of urea, above $3 \mathrm{~g} / \mathrm{dL}$ (Fig. S4). For the pristine $\mathrm{Ti}_{3} \mathrm{C}_{2} \mathrm{~T}_{x} \mathrm{MXene}$, no functional groups were detected in the FTIR spectra (Fig. S4).

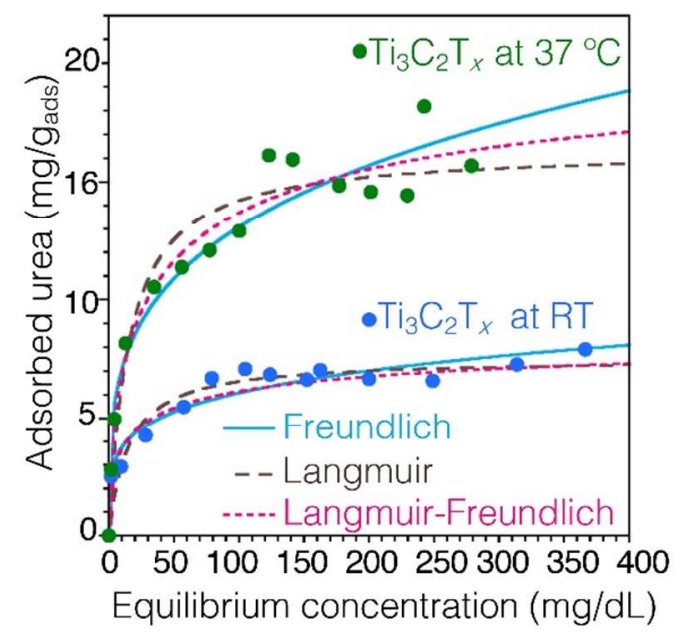

Figure 3. Urea adsorption isotherms from aqueous solution on $2 \mathrm{D}$ titanium carbide $\left(\mathrm{Ti}_{3} \mathrm{C}_{2} \mathrm{~T}_{x}\right)$ at room temperature and $37^{\circ} \mathrm{C}$. The experimental adsorption data (filled blue circles) were fitted by Freundlich (solid lightblue line), Langmuir (dashed brown line) and Langmuir-Freundlich (dotted pink line) adsorption isotherm equations.

One can argue that urea can be decomposed on MXene surfaces similar to other materials used for urea removal according to Eq. (1). A recent study reported partial decomposition of urea to ammonium and $\mathrm{CO}_{2}$ while mixing with $\mathrm{Ti}_{3} \mathrm{C}_{2} \mathrm{~T}_{x}$ MXene powder at $60{ }^{\circ} \mathrm{C}$ for $15 \mathrm{~h} .{ }^{35}$ To further investigate whether MXene flakes adsorb urea or decompose it, we performed thermal gravimetric (TG) analysis with mass spectroscopy (MS) from room temperature to $1000{ }^{\circ} \mathrm{C}$ on $\mathrm{Ti}_{3} \mathrm{C}_{2} \mathrm{~T}_{x}$ MXene powder after 1 hour adsorption experiment in the aqueous solution at low (30 mg/dL, Fig. 4a, b) and high (3 g/dL, Fig. 4c, d) urea concentrations, which are referred to as LU$\mathrm{Ti}_{3} \mathrm{C}_{2} \mathrm{~T}_{x}$ and $\mathrm{HU}-\mathrm{Ti}_{3} \mathrm{C}_{2} \mathrm{~T}_{x}$, respectively. Details of the experiment can be found in the Supporting Information. We observed two regions for the weight loss (Fig. 4a, c): between $130-250{ }^{\circ} \mathrm{C}$ and $250-550{ }^{\circ} \mathrm{C}$. The weight loss in the former temperature region for $\mathrm{HU}_{-} \mathrm{Ti}_{3} \mathrm{C}_{2} \mathrm{~T}_{x}$ (Fig. 4c) is 9.2 wt.\%, which can be associated to the thermal decomposition of urea and is close to the measured amount of adsorbed urea (Fig. S3 and Fig. 4b). In LU-Ti ${ }_{3} \mathrm{C}_{2} \mathrm{~T}_{x}$ (Fig. 4a), the measured weight 
loss is higher than that of the measured adsorbed urea, possibly due to the removal of intercalated water with urea in this sample. There is another weight loss region above $800{ }^{\circ} \mathrm{C}$ in both samples, which corresponds to the loss of surface functionalities due to a phase transformation of $2 \mathrm{D} \mathrm{Ti}_{3} \mathrm{C}_{2} \mathrm{~T}_{x}$ MXene. ${ }^{36}$

The presence of water co-intercalated with urea in the sample immersed in a lowconcentration solution is confirmed by comparing the TG-MS results of $\mathrm{LU}_{-} \mathrm{Ti}_{3} \mathrm{C}_{2} \mathrm{~T}_{x}$ and $\mathrm{HU}$ $\mathrm{Ti}_{3} \mathrm{C}_{2} \mathrm{~T}_{x}$ (Fig. 4b, d). We detected a very strong peak for the atomic mass units $(a m u)$ of $18\left(\mathrm{H}_{2} \mathrm{O}\right)$ at $\sim 100{ }^{\circ} \mathrm{C}$ and a peak for $44\left(\mathrm{C}(\mathrm{O})-\mathrm{NH}_{2}\right)$ at $\geq 200{ }^{\circ} \mathrm{C}$ in $\mathrm{LU}_{-} \mathrm{Ti}_{3} \mathrm{C}_{2} \mathrm{~T}_{x}$ sample (Fig. $\left.4 \mathrm{~b}\right)$. However, in $\mathrm{HU}-\mathrm{Ti}_{3} \mathrm{C}_{2} \mathrm{~T}_{x}$ water amu is weaker and two very strong amu of $16\left(\mathrm{NH}_{2}\right)$ and $17\left(\mathrm{NH}_{3}\right)$ and stronger $\mathrm{C}(\mathrm{O})-\mathrm{NH}_{2} a m u$ are detected in the $130-250{ }^{\circ} \mathrm{C}$ range (Fig. $4 \mathrm{~d}$ ), showing that water molecules between $\mathrm{Ti}_{3} \mathrm{C}_{2} \mathrm{~T}_{x}$ MXene flakes are replaced by urea molecules when urea concentration is increased, a clear indication of urea adsorption and not decomposition. The weight loss in the $130-250{ }^{\circ} \mathrm{C}$ temperature range is associated with urea vaporization and decomposition. The gradual mass loss between $250-550{ }^{\circ} \mathrm{C}$ is related to continued decomposition and sublimation of by-products of urea degradation (residual cyanuric acid, and ammelide and ammeline), as described by Schaber et al. ${ }^{37}$ Our TG-MS results show no evidence of urea loss below its usual decomposition temperature $\left(<130{ }^{\circ} \mathrm{C}\right)$, an indication that $\mathrm{Ti}_{3} \mathrm{C}_{2} \mathrm{~T}_{x}$ MXene does not decompose urea. Only after increasing the temperature above $130{ }^{\circ} \mathrm{C}$ we observed decomposition of the adsorbed urea on $\mathrm{Ti}_{3} \mathrm{C}_{2} \mathrm{~T}_{x}$ MXene surfaces. A possible reason for $\mathrm{CO}_{2}$ detection in the previous study ${ }^{35}$ might be the higher temperature $\left(60^{\circ} \mathrm{C}\right)$ or much longer time $(15 \mathrm{~h})$ of reaction. Additionally, we recorded the urea adsorption isotherm from aqueous solution at $60{ }^{\circ} \mathrm{C}$ (Fig. S2 and Table S1) and found a slight decrease in urea adsorption capacity, $q_{\mathrm{o}}(17.2 \mathrm{mg} / \mathrm{g})$ compared to tests performed at $37{ }^{\circ} \mathrm{C}(21.7 \mathrm{mg} / \mathrm{g})$. The small decrease in urea 
adsorption capacity at $60{ }^{\circ} \mathrm{C}$ can be due to the removal of interlayer water from $\mathrm{Ti}_{3} \mathrm{C}_{2} \mathrm{~T}_{x}$ during incubation at $60{ }^{\circ} \mathrm{C}$ (see Methods section) prior to adsorption because intercalated water in the layered structure facilitates adsorption of urea by opening the interlayer space.
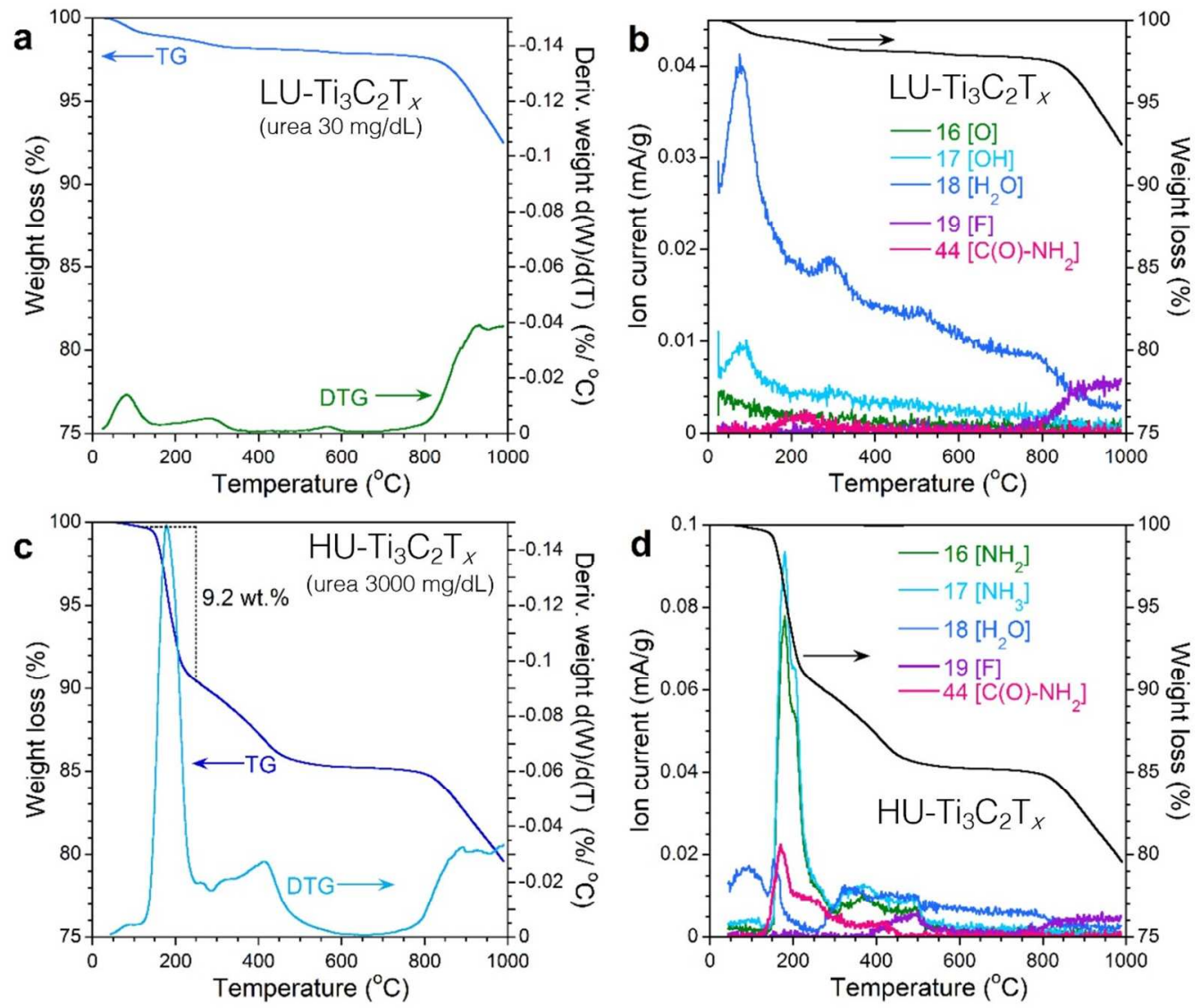

Figure 4. Thermal gravimetric with mass spectroscopy (TG-MS) analysis of $\mathrm{Ti}_{3} \mathrm{C}_{2} \mathrm{~T}_{\boldsymbol{x}}$ powder after urea adsorption from aqueous solutions. $(\mathrm{a}, \mathrm{b}) \mathrm{TG}-\mathrm{MS}$ analysis of $\mathrm{Ti}_{3} \mathrm{C}_{2} \mathrm{~T}_{x}$ powder after adsorption of urea at initial concentration of $30 \mathrm{mg} / \mathrm{dL}$, referred to as low urea $\mathrm{Ti}_{3} \mathrm{C}_{2} \mathrm{~T}_{x}\left(\mathrm{LU}-\mathrm{Ti}_{3} \mathrm{C}_{2} \mathrm{~T}_{x}\right)$, and (c, d) TG-MS analysis of $\mathrm{Ti}_{3} \mathrm{C}_{2} \mathrm{~T}_{x}$ powder after adsorption of urea at initial concentration of $3000 \mathrm{mg} / \mathrm{dL}$, referred to as high urea $\mathrm{Ti}_{3} \mathrm{C}_{2} \mathrm{~T}_{x}(\mathrm{HU}-$ $\mathrm{Ti}_{3} \mathrm{C}_{2} \mathrm{~T}_{x}$.

To further shed light on the mechanism of urea adsorption, we performed FTIR on a pristine urea solution in water (concentration of $500 \mathrm{mg} / \mathrm{dL}$ ) as well as a solution after the adsorption process by $\mathrm{Ti}_{3} \mathrm{C}_{2} \mathrm{~T}_{x}$ MXene $(\sim 400 \mathrm{mg} / \mathrm{dL})$ (Fig. S5a). We also evaporated the water in both solutions at $100{ }^{\circ} \mathrm{C}$ in air and compared the FTIR spectra of the remaining powders (Fig. S5b). Comparing the FTIR of the pure urea in water with the solution after adsorption, as well as their 
powders show no changes in the urea structure, confirming that urea does not decompose upon contacting with $\mathrm{Ti}_{3} \mathrm{C}_{2} \mathrm{~T}_{x}$ MXene powder. The reduced intensity of the urea FTIR peaks after adsorption is the result of a partial removal of urea by MXene particles.

Urea adsorption from dialysate. To assess the potential of practical use of $\mathrm{Ti}_{3} \mathrm{C}_{2} \mathrm{~T}_{x}$ in dialysate regeneration, the urea adsorption from the dialysate of patients with chronic kidney disease was studied (Fig. 5a). The experiments were done similarly to those described for the aqueous solution of urea. The data presented in Fig. $5 b$ show the effect of mass-loading of $\mathrm{Ti}_{3} \mathrm{C}_{2} \mathrm{~T}_{x}$ on the removal efficiency of urea in dialysate. For higher $\mathrm{Ti}_{3} \mathrm{C}_{2} \mathrm{~T}_{x}$ mass loadings of $5 \mathrm{~g}$, urea adsorption efficiency did not differ significantly between dialysate (94\%) and aqueous solution (99\%) (compare Figs. $2 \mathrm{c}$ and $5 \mathrm{c}$ ). However, lower mass loadings of $\mathrm{Ti}_{3} \mathrm{C}_{2} \mathrm{~T}_{x}$ MXene, have a smaller effect on urea concentration in dialysate. At $0.155 \mathrm{~g}$, the removal efficiency of urea from dialysate was less than $20 \%$, a significant decrease compared to the adsorption of urea from aqueous solution at $80 \%$ efficiency. At $37^{\circ} \mathrm{C}$ and mass loading of $0.155 \mathrm{~g}$, a twofold increase in urea adsorption efficiency was found.

Similar to the aqueous solution, $\mathrm{Ti}_{3} \mathrm{C}_{2} \mathrm{~T}_{x}$ showed fast adsorption kinetics removing urea from discarded spent dialysate mainly within the first 4 minutes (Fig. 5d). However, its adsorption capacity for urea from dialysate at low $\mathrm{Ti}_{3} \mathrm{C}_{2} \mathrm{~T}_{x}$ mass-loading of $0.155 \mathrm{~g}$ is significantly lower $(1.6 \mathrm{mg} / \mathrm{g})$ than that from aqueous solution $(9.7 \mathrm{mg} / \mathrm{g})$. Similar adsorption behavior was observed for $\mathrm{Ti}_{2} \mathrm{CT}_{x}$ and $\mathrm{Mo}_{2} \mathrm{TiC}_{2} \mathrm{~T}_{x}$ MXenes (Fig. 5d) with a fast and efficient removal within 4 minutes, but lower adsorption capacities in comparison to their capacities in aqueous solution. $\mathrm{Ti}_{3} \mathrm{C}_{2} \mathrm{~T}_{x}$ is the best MXene adsorbent for urea both from spent dialysate and water, consistently outperforming $\mathrm{Ti}_{2} \mathrm{CT}_{x}$ and $\mathrm{Mo}_{2} \mathrm{TiC}_{2} \mathrm{~T}_{x}$ (Fig. 5e). The lower adsorption capacity in spent dialysate compared to aqueous solution (compare Figs. $2 \mathrm{~d}$ and $5 \mathrm{~d}$ ) at lower adsorbent mass to solution 
volume ratio is likely to be related to the competitive adsorption of other species present in the dialysate. However, at higher mass-to-volume ratio the efficiency of urea removal by $\mathrm{Ti}_{3} \mathrm{C}_{2} \mathrm{~T}_{x}$ from water and dialysate was similar indicating the selectivity of urea adsorption and a potential of $\mathrm{Ti}_{3} \mathrm{C}_{2} \mathrm{~T}_{x}$ as urea sorbent.
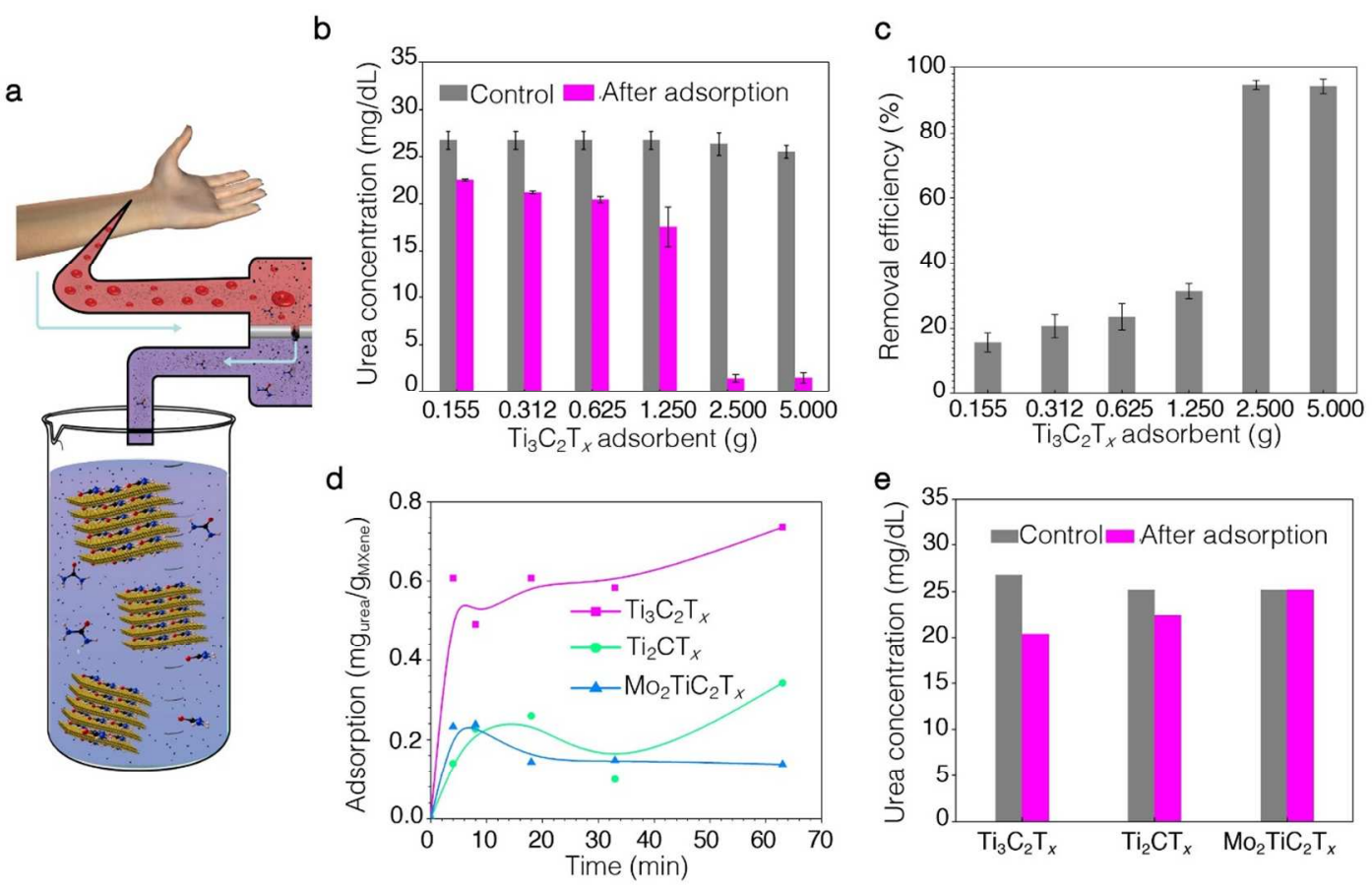

Figure 5. Urea adsorption on 2D titanium carbide MXenes from patient's dialysate. (a) Schematic of 2D titanium carbide flakes as adsorbent for urea in dialysate. (b) Changes in urea concentration in dialysate upon adsorption by $\mathrm{Ti}_{3} \mathrm{C}_{2} \mathrm{~T}_{x}$ at different mass-loadings (purple), compared to the control (gray). (c) Urea removal efficiency in \%, from dialysate using different mass-loadings of $\mathrm{Ti}_{3} \mathrm{C}_{2} \mathrm{~T}_{x}$ as adsorbent. (d) Comparison of urea uptake from dialysate after 1-hour adsorption using different MXenes, two types of titanium carbide $\left(\mathrm{Ti}_{3} \mathrm{C}_{2} \mathrm{~T}_{x}\right.$, circles and $\mathrm{Ti}_{2} \mathrm{CT}_{\mathrm{x}}$, triangles) and molybdenum titanium carbide $\left(\mathrm{Mo}_{2} \mathrm{TiC}_{2} \mathrm{~T}_{x}\right.$, squares). MXene mass-loadings were $0.155 \mathrm{~g}$ in 6 $\mathrm{mL}$ of discarded spent dialysate. (e) Comparison of urea concentrations change in dialysate upon adsorption by $\mathrm{Ti}_{3} \mathrm{C}_{2} \mathrm{~T}_{x}, \mathrm{Ti}_{2} \mathrm{CT}_{x}$, and $\mathrm{Mo}_{2} \mathrm{TiC}_{2} \mathrm{~T}_{x}$; MXene mass-loading and adsorption time were $0.625 \mathrm{~g}$ and 4 minutes, respectively. $6 \mathrm{~mL}$ of dialysate with initial urea concentration $\sim 30 \mathrm{mg} / \mathrm{dL}$ were used in all experiments reported in the figure.

At the end of this section, it is worth noting the advantage of using MXene as a sorbent compared to activated carbon. Although AC can have similar urea adsorption capacity as $\mathrm{Ti}_{3} \mathrm{C}_{2} \mathrm{~T}_{x}$ MXene, it is not selective, and adsorbs a wide range of organic molecules, among which several are essential for life. ${ }^{38,39}$ Additionally, MXenes as transition metal carbides have high densities. 
For example, the density of $\mathrm{Ti}_{3} \mathrm{C}_{2} \mathrm{~T}_{x}\left(\sim 5 \mathrm{~g} / \mathrm{cm}^{3}\right)$ is ten times higher than that of activated carbon, which significantly reduces the required volume of sorbent material, an important parameter in designing the wearable artificial kidney.

Assessment of MXene $\mathbf{T i}_{3} \mathbf{C}_{2} \mathbf{T}_{x}$ biocompatibility. To ensure that the promising candidate sorbent does not have adverse effects, its biocompatibility was assessed using a colorimetric MTS cell viability assay, a FITC-annexin V apoptosis assay using flow cytometry and by calcein-AM/ethidium homodimer live-dead staining using confocal microscopy. In the concentration range used $(0-200 \mu \mathrm{g} / \mathrm{mL}) \mathrm{Ti}_{3} \mathrm{C}_{2} \mathrm{~T}_{x}$ MXene had no impact on $3 \mathrm{~T} 3$ fibroblast cell metabolism as measured by $\mathrm{NAD}(\mathrm{P})-\mathrm{H}$ dependent oxidoreductase enzyme mediated reduction of MTS tetrazolium dye to solubilised, colored product in viable cells (Fig. 6a). In contrast to $\mathrm{Ti}_{3} \mathrm{C}_{2} \mathrm{~T}_{x}$ MXene, the positive control material, nanoparticles (NP) of graphene oxide-silver (GO$\mathrm{Ag}$ ) induced a significant reduction in colorimetric response at concentrations of $50 \mu \mathrm{g} / \mathrm{mL}$ and above ( $p<0.001, \mathrm{n}=3,+/$ - standard error of the mean). MXene $(200 \mu \mathrm{g} / \mathrm{mL})$ did not induce early apoptosis in contrast to GO-Ag, $\mathrm{AgNP}$ and camptothecin controls, where a significant increase in early apoptotic cells was observed as measured by membrane phospholipid phosphatidylserine translocation to the outer plasma membrane and staining with FITC-annexin 5 (Fig. 6b). Although AgNP had no significant impact on MTS measured cell viability at concentrations of up to $200 \mu \mathrm{g} / \mathrm{mL}$, induction of early apoptosis was detected in this concentration range using the more sensitive flow cytometry method. Live dead staining of the cells following incubation with the different nanoparticles and visualization using confocal microscopy supported the results of the MTS and apoptosis assays with regard to MXene. At the highest concentration of $200 \mu \mathrm{g} / \mathrm{mL}$ and 24-hour incubation, $\mathrm{Ti}_{3} \mathrm{C}_{2} \mathrm{~T}_{x}$ MXene did not disrupt cell viability, as shown by confocal microscopy where cellular esterase hydrolysis of the ester bonds in non-fluorescent calcein-AM 
produced calcein positive, green fluorescence in viable cells (Fig. 6c). This was in contrast to the GO-Ag positive control where non-viable cells were membrane permeant to ethidium homodimer producing ethidium positive, red fluorescent staining (Fig. 6d).
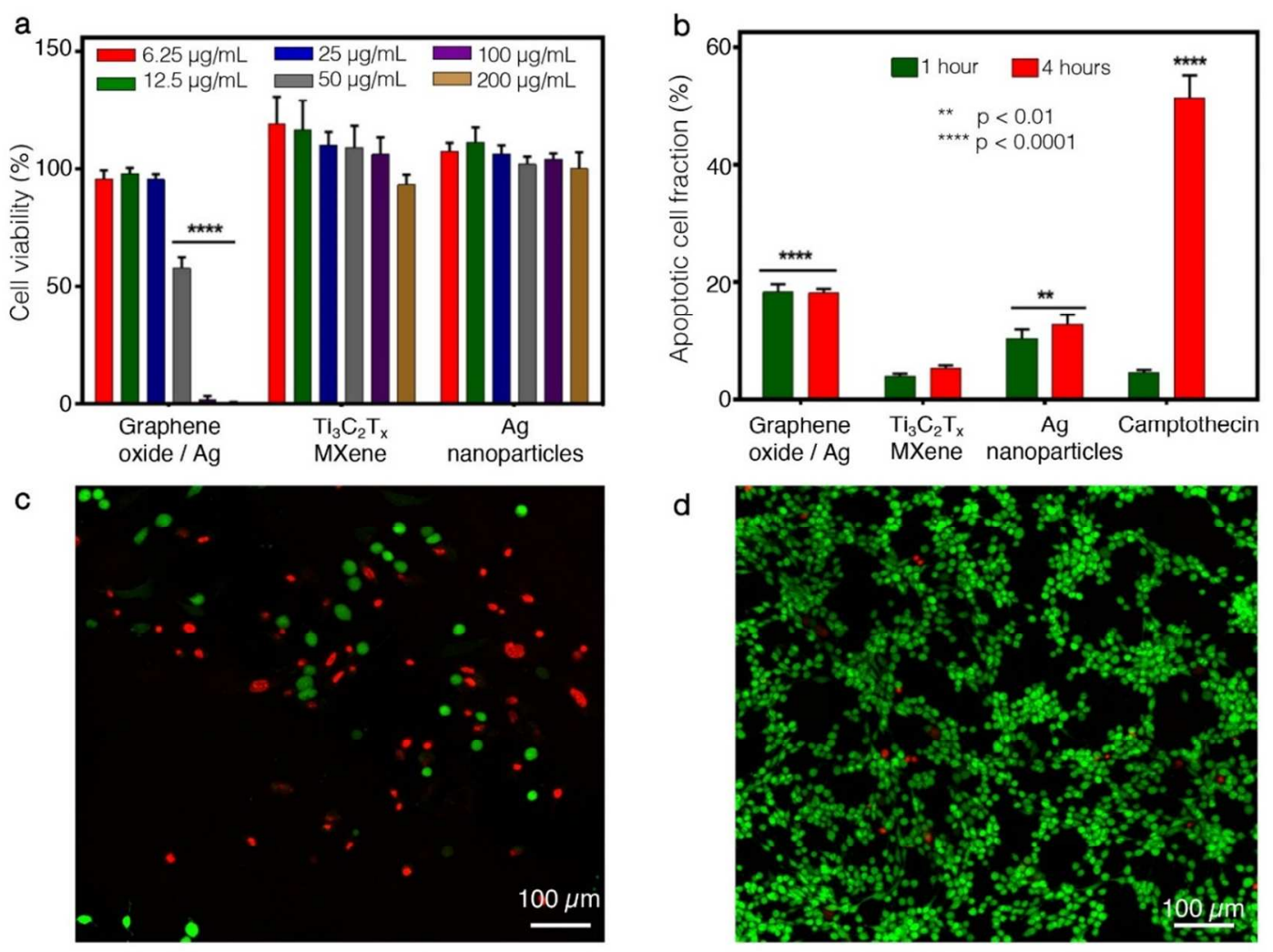

Figure 6. Assessment of $\mathrm{Ti}_{3} \mathrm{C}_{2} \mathrm{~T}_{x}$ biocompatibility using the MTS cell viability assay, FITC annexin V apoptosis detection and calcein-AM $(1 \mu \mathrm{M})$ /ethidium homodimer $(0.5 \mu \mathrm{M})$ live-dead fluorescent staining. (a) Direct contact of murine $3 \mathrm{~T} 3$ fibroblasts with $\mathrm{Ti}_{3} \mathrm{C}_{2} \mathrm{~T}_{x}$ indicated no significant reduction in cell viability following exposure to increasing concentrations of $\mathrm{Ti}_{3} \mathrm{C}_{2} \mathrm{~T}_{x}$ for $24 \mathrm{~h}$ in contrast to GO-Ag where a significant reduction occurred at the higher concentrations $(p<0.001)(\mathrm{n}=3$, mean $+/$ - standard error of the mean). (b) Exposure of Jurkat $\mathrm{T}$ cells to MXene for up to 4 hours and measurement of early apoptotic induction was carried out using annexin $\mathrm{V}$ detection of phosphatidyl serine translocation to the external cell membrane by flow cytometry. No induction of apoptosis was observed in contrast to the GO-Ag, AgNP and camptothecin $(4 \mu \mathrm{M})$ controls where significant early apoptosis was detected $(\mathrm{p}<0.01) \quad(\mathrm{n}=3$, mean $+/$ - standard error of the mean). (c) Confocal microscopy confirmed the presence of ethidium homodimer stained, red fluorescent, dead cells following exposure to GO-Ag and (d) Calcein positive, green fluorescence indicating no impact on esterase activity and thus cell viability following exposure to MXene for $24 \mathrm{~h}$ at concentrations of up to $200 \mu \mathrm{g} / \mathrm{mL}$ (x200 mag).

To assess MXene impact on the blood clotting cascades, we carried out sorbent hemocompatibility using coagulometry, hemolysis and platelet activation assays. Changes in the intrinsic, extrinsic and common blood clotting cascade were measured using changes in activated partial thromboplastin clotting time (APPT), pro-thrombin clotting time (PT) and fibrinogen 
concentration. $\mathrm{Ti}_{3} \mathrm{C}_{2} \mathrm{~T}_{x}$ MXene incubation extended the APPT clotting time but not the PT clotting time (Fig. 7a and b, respectively). No adsorption of fibrinogen (Fig. 7c) or induction of hemolysis occurred (Fig. 7d). Platelets were identified using a CD61 cell marker and the fraction of activated platelets was identified using PAC-1 and CD62p activation markers. $\mathrm{Ti}_{3} \mathrm{C}_{2} \mathrm{~T}_{x}$ MXene incubation did not induce platelet activation in comparison to the phorbol 12-myristate 13acetate (PMA) activated the positive control (Fig. 7e). The results indicate that in these batch studies, using healthy donor blood samples, $\mathrm{Ti}_{3} \mathrm{C}_{2} \mathrm{~T}_{x}$ MXene is safe to use in contact with blood. This is the first blood activation studies have been carried out for $\mathrm{Ti}_{3} \mathrm{C}_{2} \mathrm{~T}_{x}$ or any other MXene.
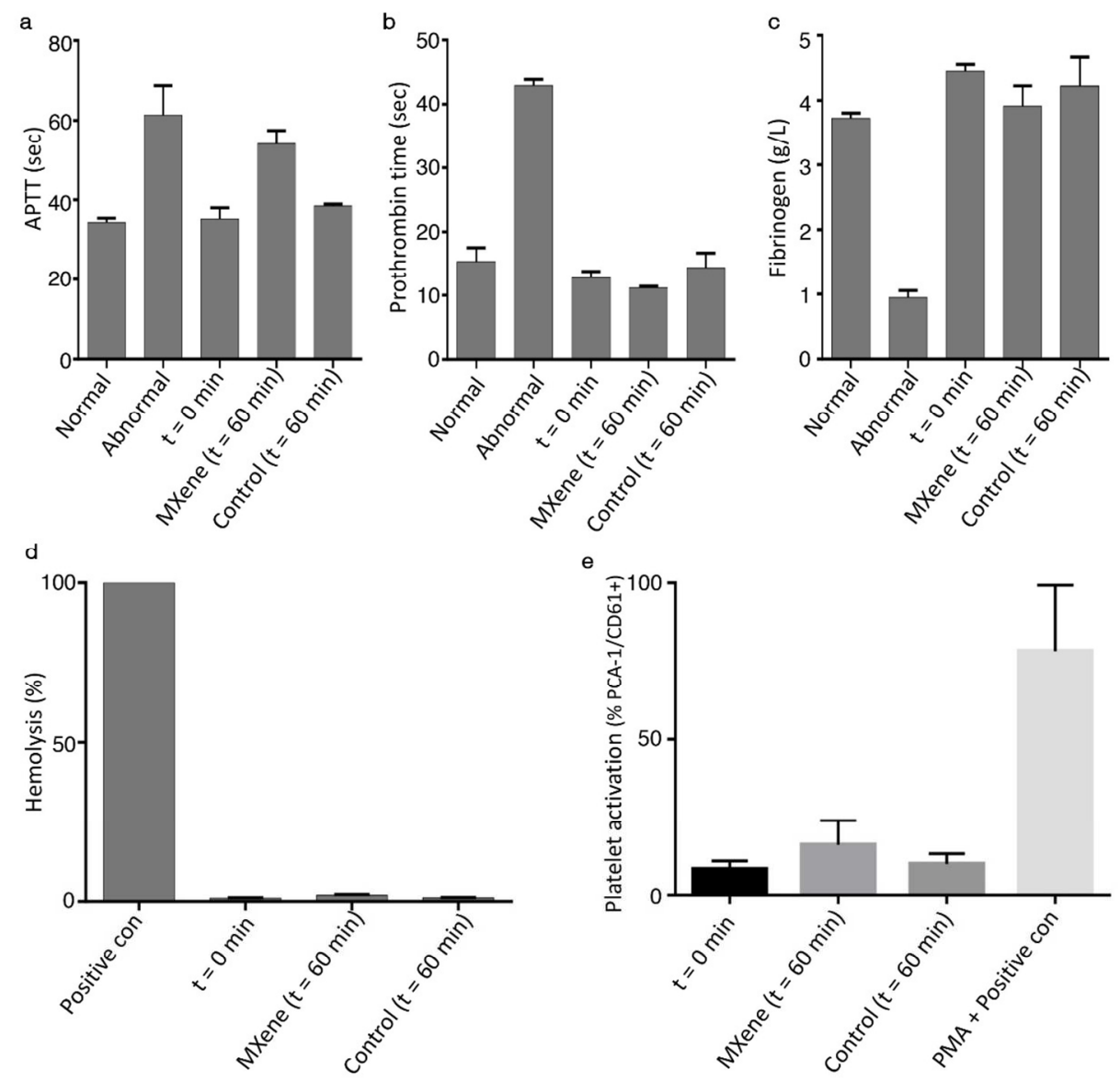

Figure 7. $\mathrm{Ti}_{3} \mathbf{C}_{2} \mathbf{T}_{x}$ MXene sorbent hemocompatibility. The hemocompatibility of $\mathrm{Ti}_{3} \mathrm{C}_{2} \mathrm{~T}_{x}$ MXene and control sample with no nanoparticles were assessed by incubation with healthy donor blood for 60 minutes followed by coagulometry, hemolysis, and flow cytometry assays to measure: a) activation of the intrinsic clotting cascade (APPT), b) activation of the extrinsic clotting cascade (PT), c) changes in blood fibrinogen concentration, d) hemolysis and e) PAC-1/CD61+ platelet activation $(n=3+$, mean $+/$ - standard error of the mean). 


\section{CONCLUSIONS}

The results of the experimental adsorption studies show rapid and selective urea removal from dialysate (at concentrations $\sim 30 \mathrm{mg} / \mathrm{dL}$ ), where the efficiency of urea removal can reach $94 \%$. First-principle calculations support stable adsorption of urea on terminated $\mathrm{Ti}_{3} \mathrm{C}_{2} \mathrm{~T}_{x}$ surfaces in both parallel and vertical orientations, with parallel urea orientation with MXene flakes being the most stable. The comparison of various MXenes showed that $\mathrm{Ti}_{3} \mathrm{C}_{2} \mathrm{~T}_{x}$ had higher adsorption capacity than $\mathrm{Ti}_{2} \mathrm{CT}_{x}$ and $\mathrm{Mo}_{2} \mathrm{TiC}_{2} \mathrm{~T}_{x}$ in both aqueous solutions and dialysate. Cytotoxicity assessment of MXene $\mathrm{Ti}_{3} \mathrm{C}_{2} \mathrm{~T}_{x}$ indicated that under the test conditions used, MXene had no significant effect on cell viability over an incubation period of 24 hours supporting the use of $\mathrm{Ti}_{3} \mathrm{C}_{2} \mathrm{~T}_{x}$ in biomedical applications. Healthy donor hemocompatibility assays indicated no impact on blood clotting, hemolysis and platelet activation following 60 minutes incubation indicating MXenes are safe to use for blood contacting applications.

The fact that the urea removal efficiency from dialysate is comparable with the $99 \%$ efficiency of removing urea from aqueous solution in the absence of competing adsorbates suggests that $\mathrm{MXene} \mathrm{Ti}_{3} \mathrm{C}_{2} \mathrm{~T}_{x}$ shows selectivity towards urea adsorption, probably owing to narrow slit pores between negatively charged MXene sheets that allow selective adsorption. Our TG-MS and FTIR analyses confirmed urea adsorption with no indication of urea decomposition on MXenes, which eliminates the need of an additional adsorbent to remove the resulting ammonia. To the best of our knowledge, this is the first report of a physical adsorbent which has such selectivity and adsorption capacity.

Our data suggest that MXene is a promising adsorbent for removing urea from dialysate. It also does not show cytotoxicity. Owing to the variety of MXenes available, it is likely that their sorption capacity towards urea can be further increased either by selecting a different MXene of 
by surface functionalization. It opens an opportunity for designing a simple and efficient WAK, which eliminates the need to use immobilized urease to hydrolyse urea and the use of an additional adsorbent to remove the resulting ammonia.

\section{EXPERIMENTAL SECTION}

Computational details of interaction between urea and MXenes and assessment of MXene $\mathrm{Ti}_{3} \mathrm{C}_{2} \mathrm{~T}_{\mathrm{x}}$ biocompatibility are explained in the Supporting Information (SI).

Materials. Urea was purchased from Sigma-Aldrich (99.9-101.0\%, calc. on dry substance) and urea assay kit (DIUR-100) from BioAssay Systems. The spent dialysate samples were collected from uremic patients (US Renal Care of West LA, Los Angeles, CA) and stored at $-80{ }^{\circ} \mathrm{C}$ until used.

MXenes $\left(\mathrm{Ti}_{3} \mathrm{C}_{2} \mathrm{~T}_{x}, \mathrm{Mo}_{2} \mathrm{TiC}_{2} \mathrm{~T}_{x}\right.$ and $\left.\mathrm{Ti}_{2} \mathrm{CT}_{x}\right)$ were synthesized from their respective precursors $\mathrm{Ti}_{3} \mathrm{AlC}_{2}, \mathrm{Mo}_{2} \mathrm{TiAlC}_{2}$ and $\mathrm{Ti}_{2} \mathrm{AlC}$. The details of precursors synthesis are explained elsewhere. ${ }^{40,41}$ To make $\mathrm{Ti}_{3} \mathrm{C}_{2} \mathrm{~T}_{x}, 5 \mathrm{~g}$ of $\mathrm{Ti}_{3} \mathrm{AlC}_{2}(<37 \mu \mathrm{m}$ particle size $)$ powder was added into $50 \mathrm{~mL}$ of $10 \%$ hydrofluoric acid (50\%, Fisher Scientific) solution over $2 \mathrm{~min}$. The solution was stirred for $24 \mathrm{~h}$ at $35{ }^{\circ} \mathrm{C}$. The multilayered $\mathrm{Ti}_{3} \mathrm{C}_{2} \mathrm{~T}_{\mathrm{x}}$ thus obtained was washed with deionized water by centrifugation and decantation until the $\mathrm{pH}$ of suspension reached $\sim 6$. Similarly, the $\mathrm{Mo}_{2} \mathrm{TiC}_{2} \mathrm{~T}_{x}$ and $\mathrm{Ti}_{2} \mathrm{CT}_{x}$ were synthesized by etching in $50 \% \mathrm{HF}$ at $55^{\circ} \mathrm{C}$ for $72 \mathrm{~h}$ and in $10 \% \mathrm{HF}$ at $35^{\circ} \mathrm{C}$ for $18 \mathrm{~h}$, respectively. After the final centrifugation, the sediment of each MXene was collected via vacuum assisted filtration and the resulting MXene powders were kept under vacuum at room temperature.

Cell studies were carried out using an ATCC murine fibroblast 3 T3 cell line (ATCC@ CRL$1658^{\mathrm{TM}}$ ) and Jurkat $\mathrm{T}$ cells (ATCC TIB-152) grown in Dulbecco's Modified Eagle Medium supplemented with fetal bovine serum $(10 \% \mathrm{v} / \mathrm{v})$. The CellTiter $96{ }^{\circledR}$ AQueous One Solution Cell 
Proliferation Assay (Promega Corporation Cat.\# G3580) was used to study the effect of MXene exposure on metabolizing cell function in comparison to a range of other nanomaterials. Graphene oxide silver (GO-Ag) was synthesized using a modified method from Das et al. ${ }^{42}$ Silver nanoparticles (AgNP) were purchased from Sigma-Aldrich, Gillingham, Dorset, UK. The FITC Annexin V apoptosis detection kit 1 was purchased from BD Pharminogen, live-dead stain containing calcein-acetoxymethyl ester (calcein-AM) and ethidium homodimer- 1 (EthD-1) was purchased from Molecular Probes Ltd.

Adsorption of urea from aqueous solution. The urea adsorption of various MXenes was first tested using aqueous solutions at ambient conditions. The initial concentration of urea in aqueous solution was $\sim 30 \mathrm{mg} / \mathrm{dL}$, which corresponds to the normal urea concentration in the discarded spent dialysate from dialysis machines (US Renal Care of West LA, Los Angeles, CA). To study the kinetics and removal efficiency, different mass-loadings of MXene $\left(\mathrm{Ti}_{3} \mathrm{C}_{2} \mathrm{~T}_{x}\right)$ powder $(5,2.5$, $1.250,0.625,0.312$ and $0.155 \mathrm{~g}$ - adsorbent dosage) were added to $6 \mathrm{~mL}$ of urea aqueous solution mixed by hand shaking ( $4 \mathrm{~min})$ and then held static. The vials containing MXene and urea solution were shaken $(150 \mathrm{rpm})$ for an hour and even longer 24 hours. It was found that the residual urea concentration in solution remains the same as after 4 min by hand shaking and then held static $60 \mathrm{~min}$ showing that the MXene/urea reached equilibrium within 4 min. For $\mathrm{Mo}_{2} \mathrm{TiC}_{2} \mathrm{~T}_{\mathrm{x}}$ and $\mathrm{Ti}_{2} \mathrm{CT}_{\mathrm{x}}$ materials, the adsorbent dosage was $0.155 \mathrm{~g}$. At 1, 5, 15, 30, and $60 \mathrm{~min}$ time points, the aliquots of urea solutions $(1 \mathrm{~mL})$ were taken using a micropipette and then centrifuged at 14,000 rpm. Afterwards, the supernatants were collected and centrifuged again $(14,000 \mathrm{rpm})$ to remove small particles of adsorbent prior to analysis. The adsorption isotherm of urea from aqueous solution was conducted only for $\mathrm{Ti}_{3} \mathrm{C}_{2} \mathrm{~T}_{x}$ at room temperature, $37{ }^{\circ} \mathrm{C}$ and 60 o $\mathrm{C}$ which showed the highest removal efficiency in kinetic experiments among all MXenes 
studied here. The same amount of $\mathrm{Ti}_{3} \mathrm{C}_{2} \mathrm{~T}_{x}(0.625 \mathrm{~g})$ was weighed and added to urea solutions (6 $\mathrm{mL}$ ) ranging in concentration from 30 to $450 \mathrm{mg} / \mathrm{dL}$. After reaching equilibrium (60 min, shaking at $150 \mathrm{rpm}$ ), the samples were centrifuged supernatants analyzed for urea content, and the equilibrium adsorption isotherm was constructed.

For urea adsorption at $37^{\circ} \mathrm{C}$ and $60{ }^{\circ} \mathrm{C}, \mathrm{Ti}_{3} \mathrm{C}_{2} \mathrm{~T}_{x}$ MXene powder $(0.635 \mathrm{~g})$ and urea aqueous solutions were equilibrated at $37{ }^{\circ} \mathrm{C}$ and $60{ }^{\circ} \mathrm{C}$ in an incubator (Barnstead Labline MaxQ Mini 4450) for $30 \mathrm{~min}$. Then the urea solutions were added to the $\mathrm{Ti}_{3} \mathrm{C}_{2} \mathrm{~T}_{x}$ powder sorbent and kept at $37^{\circ} \mathrm{C}$ and $60{ }^{\circ} \mathrm{C}$ for 1 hour.

The concentration of urea (in $\mathrm{mg} / \mathrm{dL}$ ) was determined using BioAssay Systems' urea assay kit (DIUR-100) by reading the optical density (OD) at $520 \mathrm{~nm}$ following equation:

$$
[\text { Urea }]=\frac{O D_{\text {sample }}-O D_{\text {blank }}}{O D_{\text {standard }}-O D_{\text {blank }}} \times n \times[S T D],
$$

where $O D_{\text {sample, }} O D_{\text {blank }}$ and $O D_{\text {standard }}$ are $O D$ values of sample, blank (water) and standard, respectively. The variable $n$ is the dilution factor and $[\mathrm{STD}]=50$ (or 5 for low urea samples) is the urea standard concentration (in $\mathrm{mg} / \mathrm{dL}$ ).

The amount adsorbed urea was calculated from equation:

$$
q=\frac{\left(C_{O}-C_{e}\right) \times V}{m},
$$

where $q$ is the amount of adsorbed urea $(\mathrm{mg} / \mathrm{g}), C_{\mathrm{o}}$ is the initial concentration of solute $(\mathrm{mg} / \mathrm{dL})$, $C_{\mathrm{e}}$ is the final concentration of solute at equilibrium $(\mathrm{mg} / \mathrm{dL}), V$ is the volume aliquot adsorbate $(\mathrm{mL})$ and $m$ is the mass of adsorbent $(\mathrm{g})$.

The Langmuir, Freundlich, and Langmuir-Freundlich adsorption isotherm equations were employed to fit experimental adsorption data using equations (5), (6), and (7), respectively. 


$$
\begin{aligned}
& \frac{q_{e}}{q_{o}}=\frac{K C_{e}}{\left(1+K C_{e}\right)} \\
& q=K C^{n}, \\
& \frac{q_{e}}{q_{o}}=\frac{\left(K C_{e}\right)^{n}}{1+\left(K C_{e}\right)^{n}},
\end{aligned}
$$

where $q_{\mathrm{e}}$ is the amount of urea adsorbed per gram of adsorbent at equilibrium, $q_{\mathrm{o}}$ is the maximum value of urea adsorption per gram of the adsorbent, $K$ is the Langmuir-type constant defined by the Van't Hoff equation, and the exponential term $n$ represents the heterogeneity of the site energies.

Adsorption of urea from dialysate. The removal adsorption efficiency of urea was tested directly in discarded spent dialysate from dialysis machines. The method of testing was the same as described for urea adsorption from aqueous solution. The concentration of urea $(\mathrm{mg} / \mathrm{dL})$ was determined using BioAssay Systems’ urea assay kit.

\begin{abstract}
ASSOCIATED CONTENT
Supporting Information. Supporting material includes review of urea sorbent materials reported previously; configurations and distances between two layers of MXenes before and after intercalation of urea; interaction between MXene surface and protonated urea; parameters of adsorption isotherm models for urea adsorption on $\mathrm{Ti}_{3} \mathrm{C}_{2} \mathrm{~T}_{x}$; Urea adsorption isotherms from aqueous solution at $60{ }^{\circ} \mathrm{C}$; Urea adsorption isotherm from aqueous solution at wide equilibrium concentration range (up to $3000 \mathrm{mg} / \mathrm{dL}$ ); FTIR spectra; details of computational, assessment of MXene $\mathrm{Ti}_{3} \mathrm{C}_{2} \mathrm{~T}_{x}$ biocompatibility, and thermal analysis and mass spectroscopy. The Supporting Information is available free of charge on the ACS Publications website at DOI.
\end{abstract}

\title{
AUTHOR INFORMATION
}

Corresponding Author

E-mail (B. Anasori): anasori@drexel.edu

Email (Y. Gogotsi): gogotsi@drexel.edu

\section{Authors Contributions}


Y.G., S.M., S.S., B.A. suggested to test MXenes for urea adsorption. F.M., V.G. and M.S. designed and carried out the experiments, analyzed the data. M.S. carried out the urea adsorption at $37{ }^{\circ} \mathrm{C}$ and $60{ }^{\circ} \mathrm{C}$ and analyzed the data on the urea stability. S.S., G.I. and T.O. designed, carried out and analyzed the biocompatibility data. S.M. also contributed to analyzing the data. C.C and L.M. carried out the DFT calculations. The manuscript was prepared by F.M., M.S., C.C., V.G., S.M., S.S., B.A., and Y.G. The manuscript was written through contributions of all authors. All authors have given approval to the final version of the manuscript. The authors declare no competing financial interests.

\section{Additional Information}

Fayan Meng \& Mykola Seredych contributed equally to this work.

\section{ACKNOWLEDGMENT}

This material is based upon work carried out by the NOMAD project supported by the British Council and the UK Department for Business, Innovation and Skills through the Global Innovation Initiative. MXene synthesis and characterization at Drexel University over the years were supported by various programs of the US Department of Energy. The help of Mr. Nicholas Trainer, Bernard Haines, Matthew Brodowski in MXene synthesis is greatly appreciated. We are thankful for the help of Ms. Saleesha Sin in Figure 4 schematic. We are grateful to Dr. Andrew Davenport for attracting V.G. attention to MXene, and to Prof. Michel Barsoum for helpful discussions. Fayan Meng was also supported by the Guangxi Scholarship Fund of the Guangxi Education Department, P.R. China. Chi Chen was supported by the Chinese Scholarship Council (CSC). The authors also acknowledge funding from the University of Brighton PaBS output enhancement fund. The computational resources were provided by Intelligent Electronics Institute, Huazhong University of Science and Technology, China. 


\section{REFERENCES}

1. Esrd Patients in 2013.A Global Perspective. Fresenius Medical Care, Bad Homburg. Germany 2013.

2. Fhn Trial Group in-Center Hemodialysis Six Times Per Week Versus Three Times Per Week. N. Engl. J. Med. 2010, 363, 2287-2300.

3. Davenport, A., Dialysis: A Wearable Dialysis Device: The First Step to Continuous Therapy. Nature Rev. Nephrol. 2016, 12, 512-4.

4. Kolff, W. J.; Jacobsen, S.; Stephen, R. L.; Rose, D., Towards a Wearable Artificial Kidney. Kidney Int. Supp. 1976, S300-4.

5. Davenport, A.; Gura, V.; Ronco, C.; Beizai, M.; Ezon, C.; Rambod, E., A Wearable Haemodialysis Device for Patients with End-Stage Renal Failure: A Pilot Study. Lancet 2007, 370, 2005-10.

6. Gura, V.; Beizai, M.; Ezon, C.; Polaschegg, H. D., Continuous Renal Replacement Therapy for EndStage Renal Disease. The Wearable Artificial Kidney (Wak). Contrib. Nephrol. 2005, 149, 325-33.

7. Gura, V.; Macy, A. S.; Beizai, M.; Ezon, C.; Golper, T. A., Technical Breakthroughs in the Wearable Artificial Kidney (Wak). Clin. J. Am. Soc. Nephrol. 2009, 4, 1441-8.

8. Gura, V.; Rivara, M. B.; Bieber, S.; Munshi, R.; Smith, N. C.; Linke, L.; Kundzins, J.; Beizai, M.; Ezon, C.; Kessler, L.; Himmelfarb, J., A Wearable Artificial Kidney for Patients with End-Stage Renal Disease. JCI insight 2016, 1, e86397.

9. Gura, V.; Ronco, C.; Nalesso, F.; Brendolan, A.; Beizai, M.; Ezon, C.; Davenport, A.; Rambod, E., A Wearable Hemofilter for Continuous Ambulatory Ultrafiltration. Kidney Int. 2008, 73, 497-502.

10. Stumpe, M. C.; Grubmuller, H., Aqueous Urea Solutions: Structure, Energetics, and Urea Aggregation. J. Phys. Chem. B 2007, 111, 6220-8.

11. Gordon, A.; Lewin, A.; Marantz, L.; Maxwell, M., Sorbent Regeneration of Dialysate. Kidney Int. Supp. 1976, S277-83.

12. A.D.A.M. Medical Encyclopedia A.D.A.M. Medical Encyclopedia [Internet]. Atlanta (Ga): A.D.A.M., Inc.; C2015 [Updated 2015 Jan 07; Cited 2017 Aug 06]. Available From: Http://Www.Nlm.Nih.Gov/Medlineplus/Encyclopedia.Html.

13. Naguib, M.; Kurtoglu, M.; Presser, V.; Lu, J.; Niu, J.; Heon, M.; Hultman, L.; Gogotsi, Y.; Barsoum, M. W., Two-Dimensional Nanocrystals Produced by Exfoliation of $\mathrm{Ti}_{3} \mathrm{AlC}_{2}$. Adv. Mater. 2011, 23, 424853.

14. Anasori, B.; Lukatskaya, M. R.; Gogotsi, Y., 2D Metal Carbides and Nitrides (MXenes) for Energy Storage. Nature Rev. Mater. 2017, 2, 16098.

15. Alhabeb, M.; Maleski, K.; Anasori, B.; Lelyukh, P.; Clark, L.; Sin, S.; Gogotsi, Y., Guidelines for Synthesis and Processing of $2 \mathrm{~d}$ Titanium Carbide $\left(\mathrm{Ti}_{3} \mathrm{C}_{2} \mathrm{~T}_{x}\right.$ MXene). Chem. Mater. 2017, 29, 7633-7644.

16. Wang, H.-W.; Naguib, M.; Page, K.; Wesolowski, D. J.; Gogotsi, Y., Resolving the Structure of $\mathrm{Ti}_{3} \mathrm{C}_{2} \mathrm{~T}_{x}$ MXenes through Multi-Level Structural Modeling of the Atomic Pair Distribution Function. Chem. Mater. 2015, 28, 349-359.

17. Karlsson, L. H.; Birch, J.; Halim, J.; Barsoum, M. W.; Persson, P. O., Atomically Resolved Structural and Chemical Investigation of Single MXene Sheets. Nano Lett. 2015, 15, 4955-60.

18. Hope, M. A.; Forse, A. C.; Griffith, K. J.; Lukatskaya, M. R.; Ghidiu, M.; Gogotsi, Y.; Grey, C. P., NMR Reveals the Surface Functionalisation of $\mathrm{Ti}_{3} \mathrm{C}_{2}$ MXene. Phys. Chem. Chem. Phys. 2016, 18, 50995102.

19. Halim, J.; Cook, K. M.; Naguib, M.; Eklund, P.; Gogotsi, Y.; Rosen, J.; Barsoum, M. W., X-Ray Photoelectron Spectroscopy of Select Multi-Layered Transition Metal Carbides (MXenes). Appl. Surf. Sci. 2016, 362, 406-417.

20. Ghidiu, M.; Lukatskaya, M. R.; Zhao, M. Q.; Gogotsi, Y.; Barsoum, M. W., Conductive TwoDimensional Titanium Carbide 'Clay' with High Volumetric Capacitance. Nature 2014, 516, 78-81.

21. Mashtalir, O.; Naguib, M.; Mochalin, V. N.; Dall'Agnese, Y.; Heon, M.; Barsoum, M. W.; Gogotsi, Y., Intercalation and Delamination of Layered Carbides and Carbonitrides. Nature Commun. 2013, 4, 1716. 
22. Mashtalir, O.; Cook, K. M.; Mochalin, V. N.; Crowe, M.; Barsoum, M. W.; Gogotsi, Y., Dye Adsorption and Decomposition on Two-Dimensional Titanium Carbide in Aqueous Media. J. Mater. Chem. A 2014, 2, 14334-14338.

23. Mashtalir, O.; Lukatskaya, M. R.; Zhao, M. Q.; Barsoum, M. W.; Gogotsi, Y., Amine-Assisted Delamination of $\mathrm{Nb}_{2} \mathrm{C}$ MXene for Li-Ion Energy Storage Devices. Adv. Mater. 2015, 27, 3501-6.

24. Naguib, M.; Unocic, R. R.; Armstrong, B. L.; Nanda, J., Large-Scale Delamination of Multi-Layers Transition Metal Carbides and Carbonitrides "MXenes". Dalton Trans. 2015, 44, 9353-8.

25. Anasori, B.; Xie, Y.; Beidaghi, M.; Lu, J.; Hosler, B. C.; Hultman, L.; Kent, P. R.; Gogotsi, Y.; Barsoum, M. W., Two-Dimensional, Ordered, Double Transition Metals Carbides (MXenes). ACS Nano 2015, 9, 9507-16.

26. Sharma, G.; Muthuswamy, E.; Naguib, M.; Gogotsi, Y.; Navrotsky, A.; Wu, D., Calorimetric Study of Alkali Metal Ion $\left(\mathrm{K}^{+}, \mathrm{Na}^{+}, \mathrm{Li}^{+}\right)$Exchange in a Clay-Like MXene. J. Phys. Chem. C 2017, 121, 1514515153.

27. Olah, G. A.; White, A. M., Stable Carbonium Ions. LXIX: Protonation of Ureas, Guanidines, and Biotin in Super Acid Solution. J. Am. Chem. Soc. 1968, 90, 6087-6091.

28. Wen, N. P.; Brooker, M. H., Urea Protonation Raman and Theoretical Study. J. Phys. Chem. 1993, 97, 8608-8616.

29. Ji, H.; Bachmanov, A. A., Differences in Postingestive Metabolism of Glutamate and Glycine between C57bl/6byj and 129p3/J Mice. Physiol. Genomics 2007, 31, 475-82.

30. Roelandt, P.; Sancho-Bru, P.; Pauwelyn, K.; Verfaillie, C., Differentiation of Rat Multipotent Adult Progenitor Cells to Functional Hepatocyte-Like Cells by Mimicking Embryonic Liver Development. Nature Protoc. 2010, 5, 1324-36.

31. Jung, D.; Biggs, H.; Erikson, J.; Ledyard, P. U., New Colorimetric Reaction for End-Point, Continuous-Flow, and Kinetic Measurement of Urea. Clin. Chem. 1975, 21, 1136-40.

32. Hameed, B. H.; Din, A. T.; Ahmad, A. L., Adsorption of Methylene Blue onto Bamboo-Based Activated Carbon: Kinetics and Equilibrium Studies. J. Hazard. Mater. 2007, 141, 819-25.

33. Desta, M. B., Batch Sorption Experiments: Langmuir and Freundlich Isotherm Studies for the Adsorption of Textile Metal Ions onto Teff Straw (Eragrostis Tef) Agricultural Waste. J. Thermodyn. 2013, 2013, 1-6.

34. Nassar, M. Y.; Ali, E. I.; Zakaria, E. S., Tunable Auto-Combustion Preparation of $\mathrm{TiO}_{2}$ nanostructures as Efficient Adsorbents for the Removal of an Anionic Textile Dye. RSC Adv. 2017, 7, 8034-8050.

35. Overbury, S. H.; Kolesnikov, A. I.; Brown, G. M.; Zhang, Z.; Nair, G. S.; Sacci, R. L.; Lotfi, R.; van Duin, A. C.; Naguib, M., Complexity of Intercalation in MXenes: Destabilization of Urea by TwoDimensional Titanium Carbide. J. Am. Chem. Soc. 2018, 140, 10305-10314.

36. Mashtalir, O.; Lukatskaya, M. R.; Kolesnikov, A. I.; Raymundo-Piñero; Naguib, M.; Barsoum, M. W.; Gogotsi, Y., The Effect of Hydrazine Intercalation on Structure and Capacitance of 2D Titanium Carbide (MXene). Nanoscale 2016, 8, 9128-9133.

37. Schaber, P. M.; Colson, J.; Higgins, S.; Thielen, D.; Anspach, B.; Brauer, J., Thermal Decomposition (Pyrolysis) of Urea in an Open Reaction Vessel. Thermochim. Acta 2004, 424, 131-142.

38. Wernert, V.; Schäf, O.; Ghobarkar, H.; Denoyel, R., Adsorption Properties of Zeolites for Artificial Kidney Applications. Microporous Mesoporous Mater. 2005, 83, 101-113.

39. Bansal, R. C.; Donnet, J.-B.; Stoeckli, F., Active Carbon. Marcel Dekker: 1988.

40. Shahzad, F.; Alhabeb, M.; Hatter, C. B.; Anasori, B.; Man Hong, S.; Koo, C. M.; Gogotsi, Y., Electromagnetic Interference Shielding with 2D Transition Metal Carbides (MXenes). Science 2016, 353, 1137-40.

41. Anasori, B.; Dahlqvist, M.; Halim, J.; Moon, E. J.; Lu, J.; Hosler, B. C.; Caspi, E. a. N.; May, S. J.; Hultman, L.; Eklund, P.; Rosén, J.; Barsoum, M. W., Experimental and Theoretical Characterization of Ordered MAX Phases $\mathrm{Mo}_{2} \mathrm{TiAlC}_{2}$ and $\mathrm{Mo}_{2} \mathrm{Ti}_{2} \mathrm{AlC}_{3}$. J. App. Phys. 2015, 118, 094304. 
42. Das, M. R.; Sarma, R. K.; Saikia, R.; Kale, V. S.; Shelke, M. V.; Sengupta, P., Synthesis of Silver Nanoparticles in an Aqueous Suspension of Graphene Oxide Sheets and Its Antimicrobial Activity. Colloids Surf. B 2011, 83, 16-22. 
a

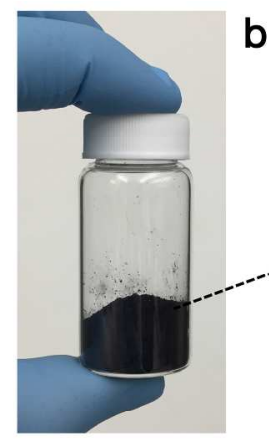

b
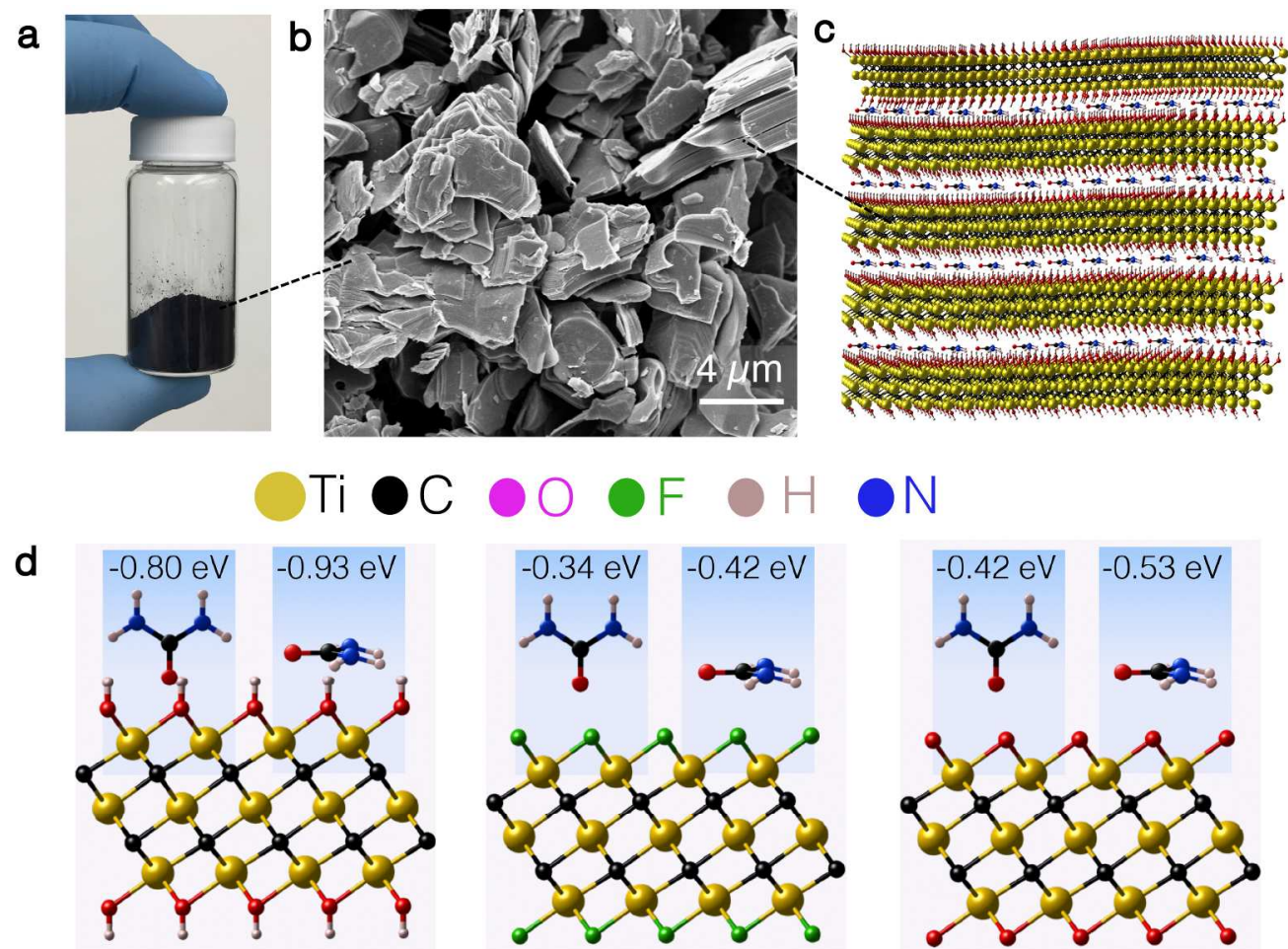

N
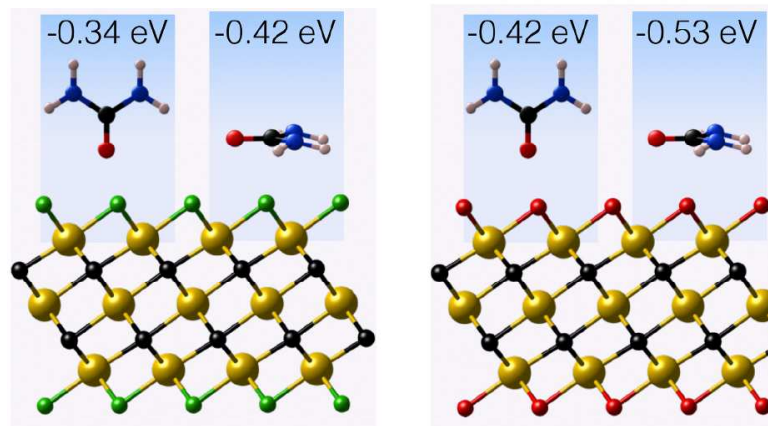

e
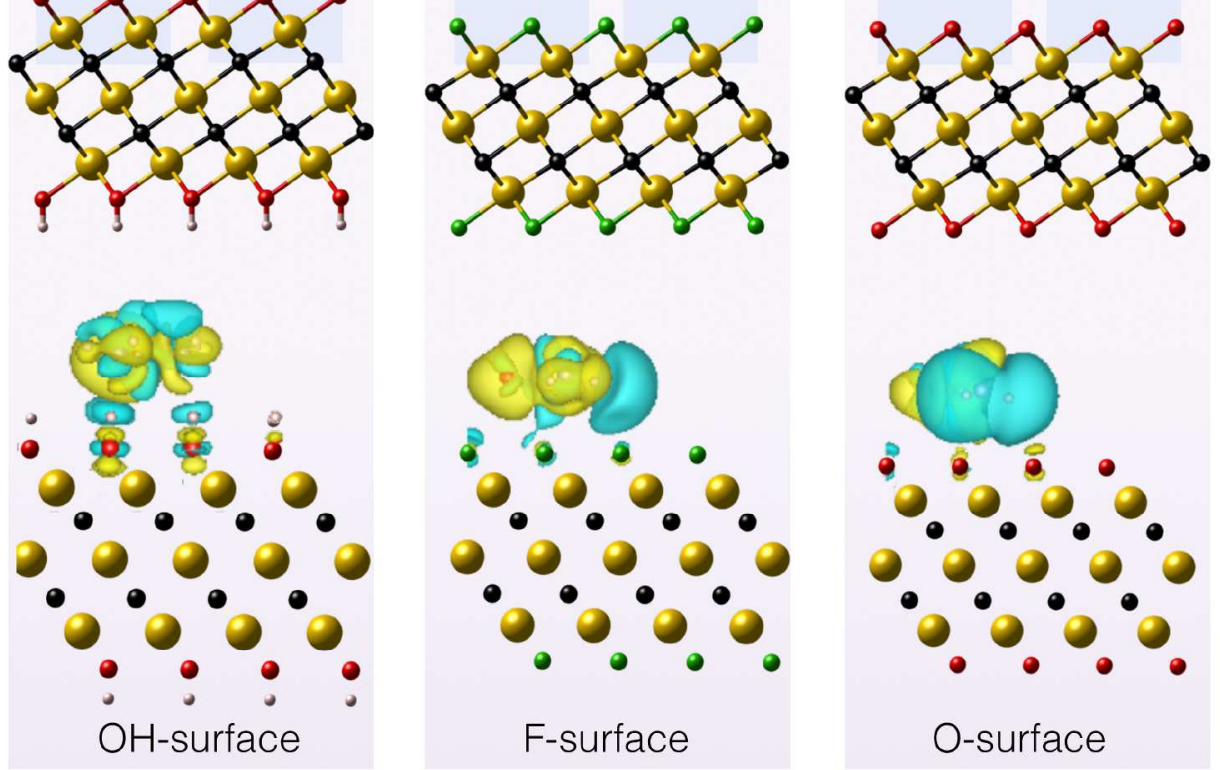

Figure 1. Schematic representation of Ti3C2Tx MXene, urea and their interaction computations. (a) digital photograph of $\sim 7$ grams of Ti3C2Tx powder in a 20-mL glass vial. (b) Scanning electron microscopy image of the Ti3C2Tx powder. (c) Schematic of Ti3C2Tx MXene powder intercalated with urea molecules. (d) Binding energies for normal and parallel configurations of urea on Ti3C2Tx surfaces for three possible MXene terminations, $-\mathrm{OH},-\mathrm{F}$, and $-\mathrm{O}-$, showing urea most stable adsorption is parallel configuration to the Ti3C2Tx MXene nanosheet. (e) Charge density for parallel configuration of urea on Ti3C2Tx MXene surface with different surface terminations, showing more charge transfer between urea and OH-terminated surfaces (left panel). The turquoise and yellow regions indicate depletion and accumulation of electrons, respectively.

$$
215 \times 249 \mathrm{~mm}(300 \times 300 \mathrm{DPI})
$$


b

a

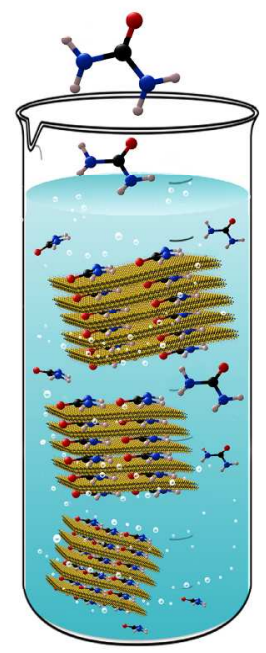

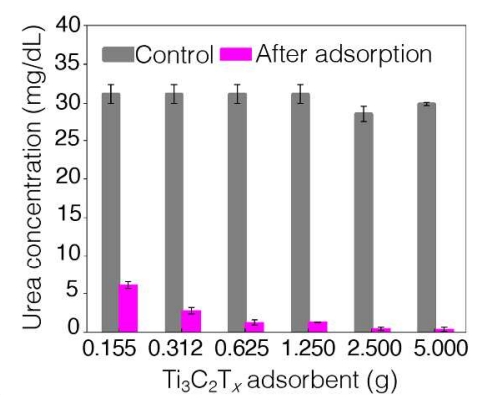

d

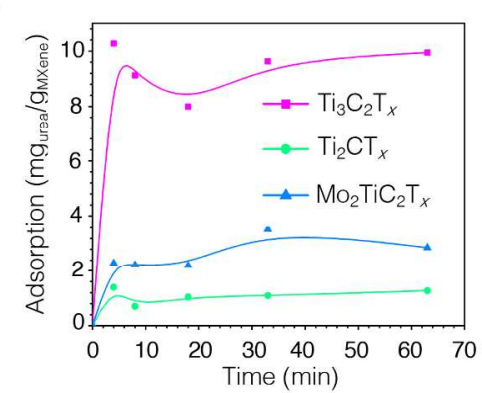

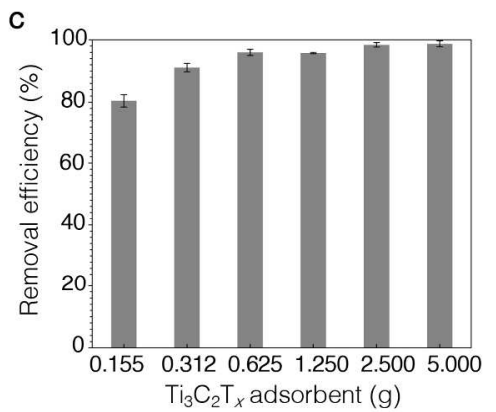

e

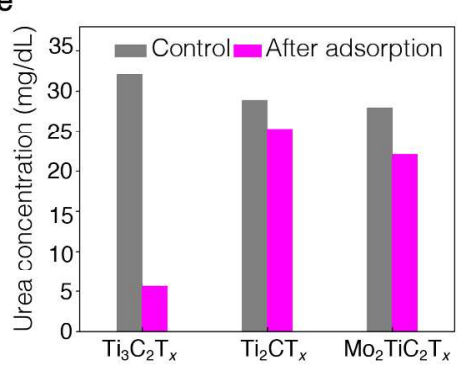

Figure 2. Adsorption of urea by MXenes from aqueous solution. (a) Schematic of MXene nanosheets used as the adsorbent. The beaker schematic is not to scale and should not be used to compare the size of MXene sheets and urea molecules. (b) Changes in urea concentration upon adsorption at different mass-loadings of Ti3C2Tx (purple), compared to the control sample (gray). For each sample, the volume was $6 \mathrm{~mL}$ of 30 $\mathrm{mg} / \mathrm{dL}$ of urea aqueous solution. The urea concentration was measured after adding MXene (contact time was $4 \mathrm{~min}$ ). (c) Urea removal efficiency in \% from aqueous solution at different mass-loadings of Ti3C2TX.

(d) Comparison of urea uptake for 1-hour adsorption using different 2D MXenes, two types of titanium carbide (Ti3C2Tx, squares and Ti2CTx, triangles) and 2D molybdenum titanium carbide (Mo2TiC2Tx, circles). MXene mass-loadings were $0.155 \mathrm{~g}$ in $6 \mathrm{~mL}$ of solution. (e) Comparison of urea concentration changes upon adsorption by Ti3C2Tx, Ti2CTx, and Mo2TiC2Tx with initial urea concentration $\sim 30 \mathrm{mg} / \mathrm{dL}$. MXene massloading and adsorption time were $0.155 \mathrm{~g}$ and 4 minutes, respectively. 




Figure 3. Urea adsorption isotherms from aqueous solution on 2D titanium carbide (Ti3C2Tx) at room temperature and $37^{\circ} \mathrm{C}$. The experimental adsorption data (filled blue circles) were fitted by Freundlich (solid light-blue line), Langmuir (dashed brown line) and Langmuir-Freundlich (dotted pink line) adsorption isotherm equations.

$215 \times 205 \mathrm{~mm}(300 \times 300 \mathrm{DPI})$ 

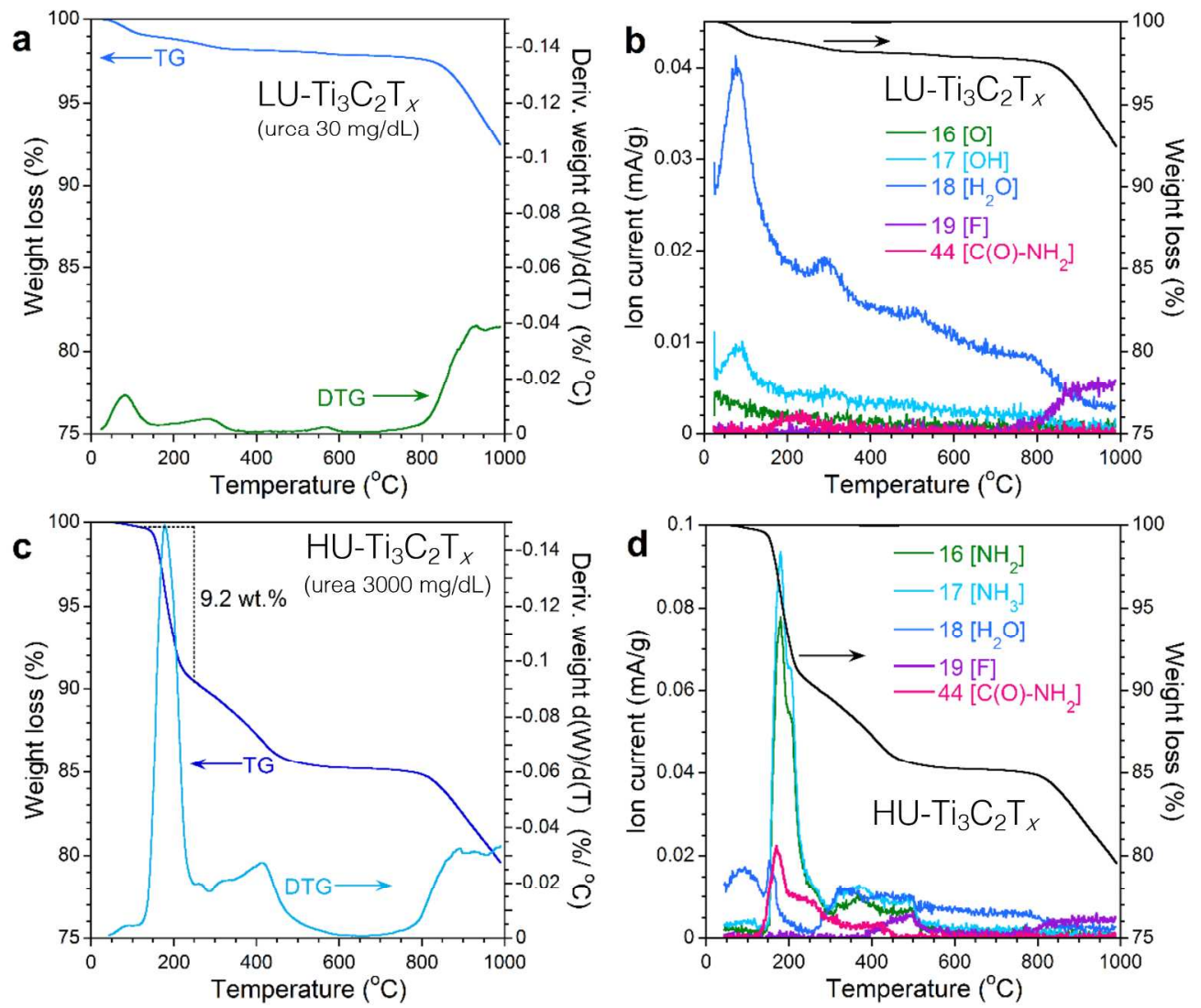

Figure 4. Thermal gravimetric with mass spectroscopy (TG-MS) analysis of Ti3C2Tx powder after urea adsorption from aqueous solutions. (a, b) TG-MS analysis of Ti3C2Tx powder after adsorption of urea at initial concentration of $30 \mathrm{mg} / \mathrm{dL}$, referred to as low urea Ti3C2Tx (LU- Ti3C2Tx), and (c, d) TG-MS analysis of Ti3C2Tx powder after adsorption of urea at initial concentration of $3000 \mathrm{mg} / \mathrm{dL}$, referred to as high urea Ti3C2Tx (HU- Ti3C2Tx). 
b

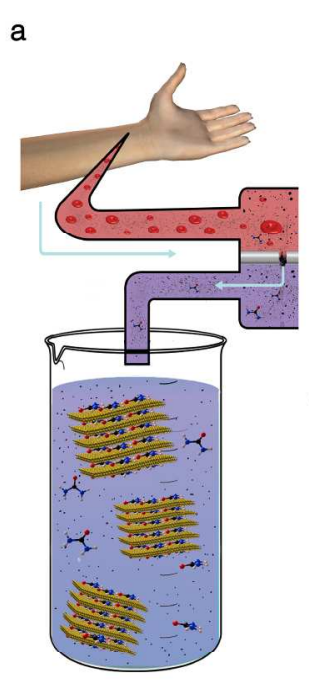

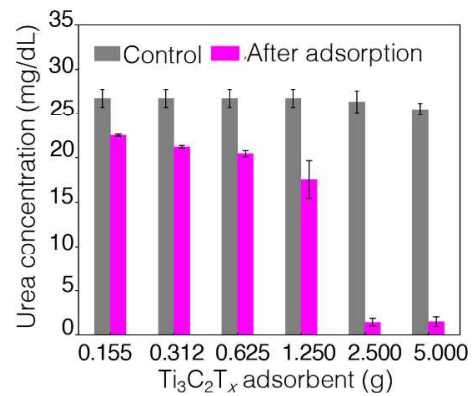

d

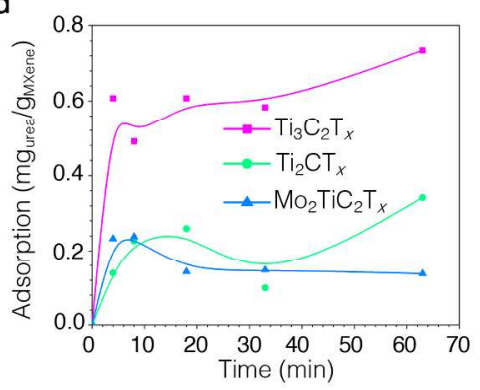

c
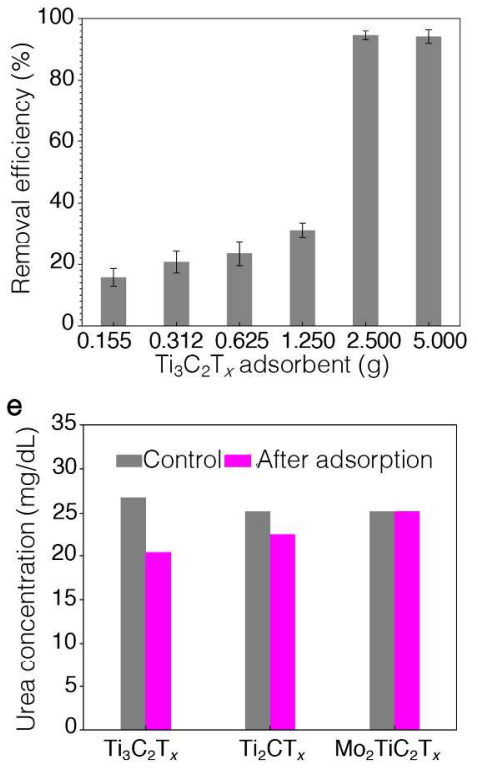

Figure 5. Urea adsorption on 2D titanium carbide MXenes from patient's dialysate. (a) Schematic of 2D titanium carbide flakes as adsorbent for urea in dialysate. (b) Changes in urea concentration in dialysate upon adsorption by Ti3C2Tx at different mass-loadings (purple), compared to the control (gray). (c) Urea

removal efficiency in \%, from dialysate using different mass-loadings of Ti3C2Tx as adsorbent. (d)

Comparison of urea uptake from dialysate after 1-hour adsorption using different MXenes, two types of titanium carbide (Ti3C2Tx, circles and Ti2CTx, triangles) and molybdenum titanium carbide (Mo2TiC2Tx, squares). MXene mass-loadings were $0.155 \mathrm{~g}$ in $6 \mathrm{~mL}$ of discarded spent dialysate. (e) Comparison of urea concentrations change in dialysate upon adsorption by Ti3C2Tx, Ti2CTx, and Mo2TiC2Tx; MXene massloading and adsorption time were $0.625 \mathrm{~g}$ and 4 minutes, respectively. $6 \mathrm{~mL}$ of dialysate with initial urea concentration $\sim 30 \mathrm{mg} / \mathrm{dL}$ were used in all experiments reported in the figure. 

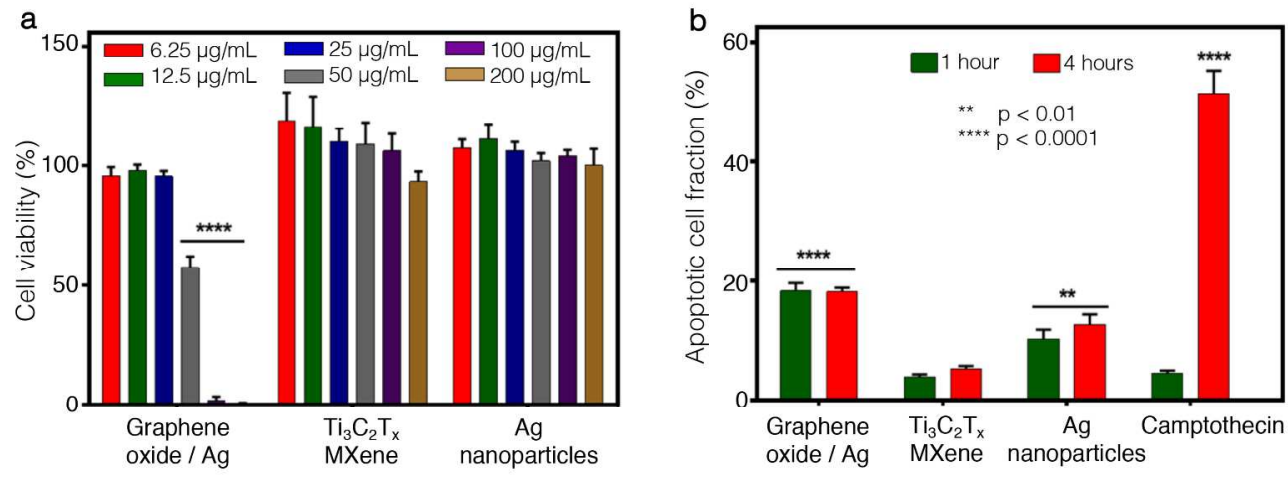

C



d

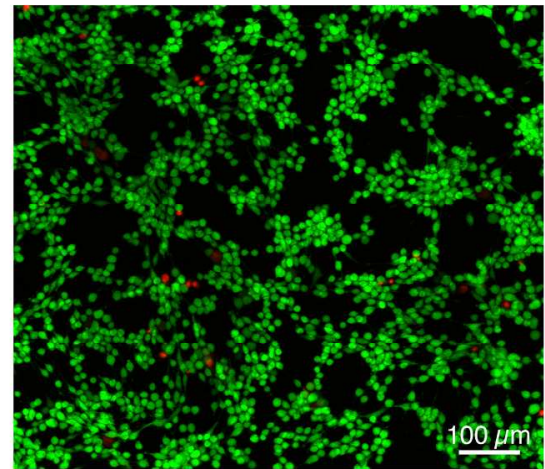

Figure 6. Assessment of Ti3C2Tx biocompatibility using the MTS cell viability assay, FITC annexin V apoptosis detection and calcein-AM $(1 \mu \mathrm{M})$ /ethidium homodimer $(0.5 \mu \mathrm{M})$ live-dead fluorescent staining. (a)

Direct contact of murine 3T3 fibroblasts with Ti3C2Tx indicated no significant reduction in cell viability following exposure to increasing concentrations of Ti3C2Tx for $24 \mathrm{~h}$ in contrast to GO-Ag where a significant reduction occurred at the higher concentrations $(p<0.001)(n=3$, mean $+/$ - standard error of the mean). (b) Exposure of Jurkat T cells to MXene for up to 4 hours and measurement of early apoptotic induction was carried out using annexin $\mathrm{V}$ detection of phosphatidyl serine translocation to the external cell membrane by flow cytometry. No induction of apoptosis was observed in contrast to the GO-Ag, AgNP and camptothecin (4 $\mu M)$ controls where significant early apoptosis was detected $(p<0.01)(n=3$, mean+/- standard error of the mean). (c) Confocal microscopy confirmed the presence of ethidium homodimer stained, red fluorescent, dead cells following exposure to GO-Ag and (d) Calcein positive, green fluorescence indicating no impact on esterase activity and thus cell viability following exposure to MXene for $24 \mathrm{~h}$ at concentrations of up to 200 $\mu \mathrm{g} / \mathrm{mL}($ x200 mag).

$215 \times 161 \mathrm{~mm}(300 \times 300$ DPI $)$ 
a

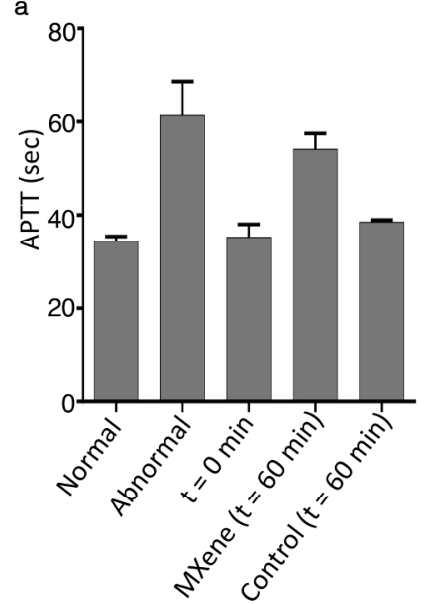

d

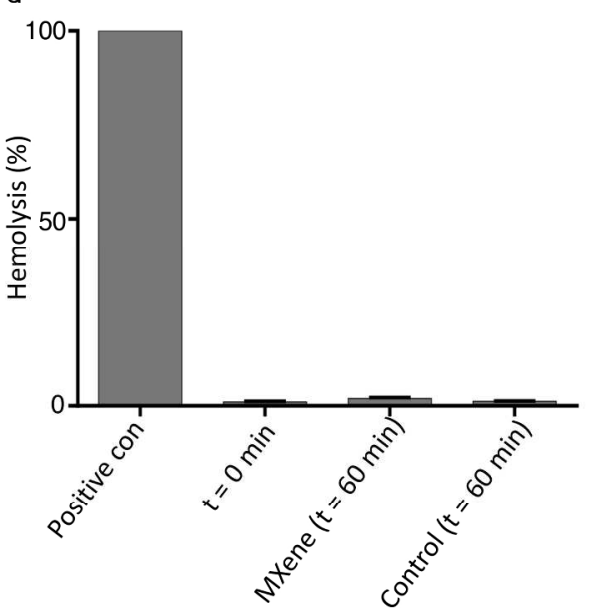

b

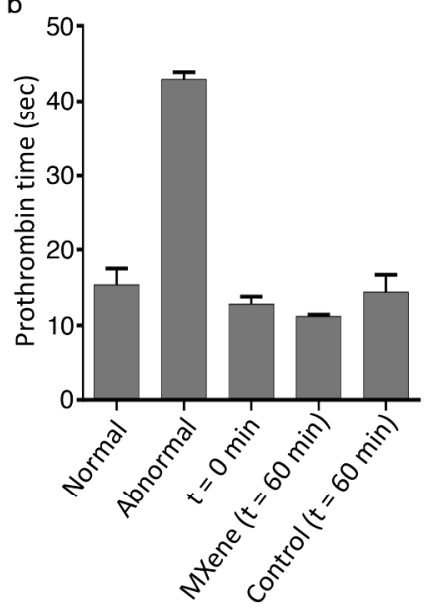

e

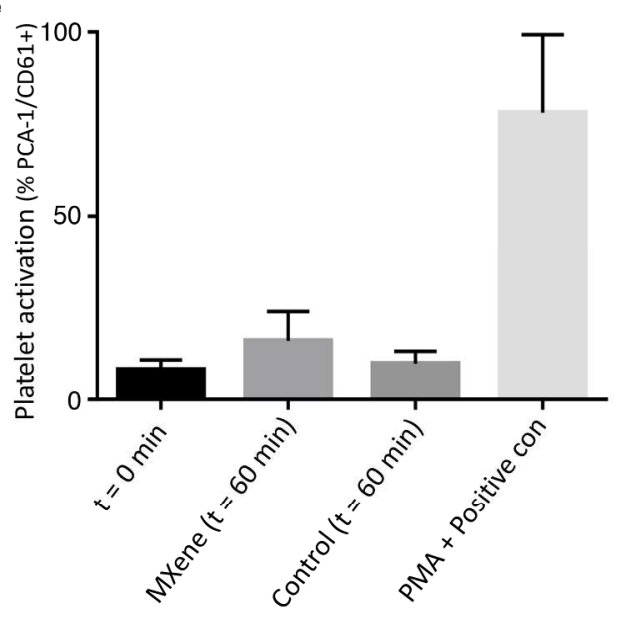

Figure 7. Ti3C2Tx sorbent haemocompatibility. The hemocompatibility of Ti3C2Tx MXene and control sample with no nanoparticles were assessed by incubation with healthy donor blood for 60 minutes followed by coagulometry, hemolysis, and flow cytometry assays to measure: a) activation of the intrinsic clotting cascade (APPT), b) activation of the extrinsic clotting cascade (PT), c) changes in blood fibrinogen concentration, d) hemolysis and e) PAC-1/CD61+ platelet activation $(n=3+$, mean $+/$ - standard error of the mean). 


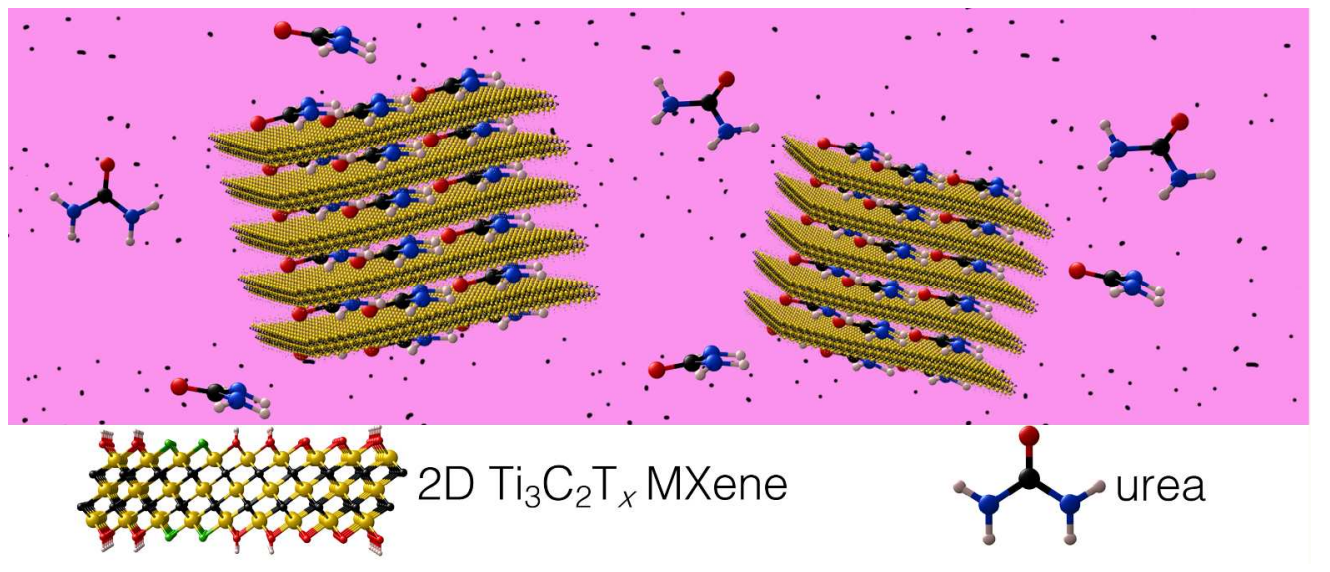

TOC graphic

$216 \times 92 \mathrm{~mm}(300 \times 300 \mathrm{DPI})$ 